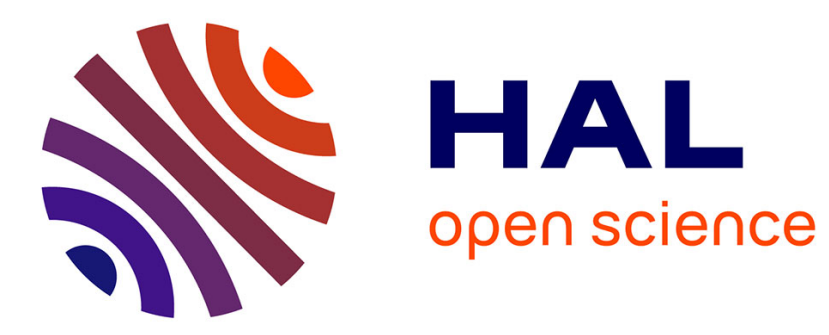

\title{
Crosstalk between the glucocorticoid receptor and other transcription factors: Molecular aspects
}

\author{
Olivier Kassel, Peter Herrlich
}

\section{To cite this version:}

Olivier Kassel, Peter Herrlich. Crosstalk between the glucocorticoid receptor and other transcription factors: Molecular aspects. Molecular and Cellular Endocrinology, 2007, 275 (1-2), pp.13. 10.1016/j.mce.2007.07.003 . hal-00531941

\section{HAL Id: hal-00531941 \\ https://hal.science/hal-00531941}

Submitted on 4 Nov 2010

HAL is a multi-disciplinary open access archive for the deposit and dissemination of scientific research documents, whether they are published or not. The documents may come from teaching and research institutions in France or abroad, or from public or private research centers.
L'archive ouverte pluridisciplinaire HAL, est destinée au dépôt et à la diffusion de documents scientifiques de niveau recherche, publiés ou non, émanant des établissements d'enseignement et de recherche français ou étrangers, des laboratoires publics ou privés. 


\section{Accepted Manuscript}

Title: Crosstalk between the glucocorticoid receptor and other transcription factors: Molecular aspects

Authors: Olivier Kassel, Peter Herrlich

PII: $\quad$ S0303-7207(07)00258-4

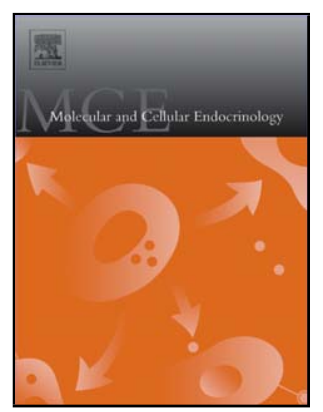

DOI: doi:10.1016/j.mce.2007.07.003

Reference: MCE 6679

To appear in: Molecular and Cellular Endocrinology

Received date:

$$
\text { 17-4-2007 }
$$

Revised date: 26-6-2007

Accepted date: 3-7-2007

Please cite this article as: Kassel, O., Herrlich, P., Crosstalk between the glucocorticoid receptor and other transcription factors: Molecular aspects, Molecular and Cellular Endocrinology (2007), doi:10.1016/j.mce.2007.07.003

This is a PDF file of an unedited manuscript that has been accepted for publication. As a service to our customers we are providing this early version of the manuscript. The manuscript will undergo copyediting, typesetting, and review of the resulting proof before it is published in its final form. Please note that during the production process errors may be discovered which could affect the content, and all legal disclaimers that apply to the journal pertain. 


\title{
Crosstalk between the glucocorticoid receptor and other
}

\author{
transcription factors: molecular aspects
}

Olivier Kassel $^{\mathrm{a}, \mathrm{c}}$ and Peter Herrlich ${ }^{\mathrm{a}, \mathrm{b}}$

\begin{abstract}
${ }^{a}$ Forschungszentrum Karlsruhe, Institute of Toxicology and Genetics,

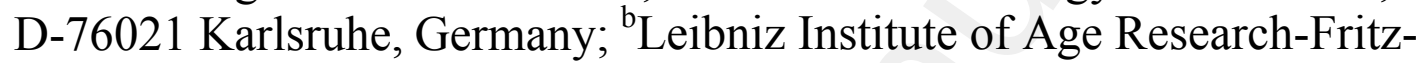
Lipmann-Institute, D-07745 Jena, Germany
\end{abstract}

Institut für Toxikologie und Genetik

Forschungszentrum Karlsruhe

Hermann-von-Helmholtz Platz 1

D - 76344 Eggenstein-Leopoldshafen

Germany

${ }^{\mathrm{c}}$ Corresponding author:

Phone: +49 (0)7247 823911

Fax: +49 (0)724782-3354

Email: Olivier.Kassel@itg.fzk.de 
Keywords: Glucocorticoid receptor, crosstalk, transcription, trans-repression, AP-1, NF$\kappa \mathrm{B}$

\begin{abstract}
:
Glucocorticoids (GCs) regulate cell fate by altering gene expression via the glucocorticoid receptor (GR). Ligand-bound GR can activate the transcription of genes carrying the specific GR binding sequence, the glucocorticoid response element (GRE). In addition, GR can modulate, positively or negatively, directly or indirectly, the activity of other transcription factors (TFs), a process referred to as "crosstalk". In the indirect crosstalk, GR interferes with transduction pathways upstream of other TFs. In the direct crosstalk, GR and other TFs modulate each other's activity when bound to the promoters of their target genes. The multiplicity of molecular actions exerted by TFs, particularly the GR, is not only fascinating in terms of molecular structure, it also implies that the TFs participate in a wide range of regulatory processes, broader than anticipated. This review focuses on the molecular mechanisms involved in the crosstalk, on both current ideas and unresolved questions, and discusses the possible significance of the crosstalk for the physiologic and therapeutic actions of GCs.
\end{abstract}


Cortisol, the natural glucocorticoid (GC) hormone in humans, as well as the numerous synthetic GCs used in therapy, exert a plethora of effects in the body. GCs for instance influence glucose and lipid metabolism, bone homeostasis, the response of the body to stress, hematopoietic differentiation, immune and inflammatory responses, but also behavioral endpoints (reviewed in Kellendonk et al., 2002; Tuckermann et al., 2005). Some of these hormonal actions account for the beneficial effects of GCs in therapy, e.g. of inflammatory disorders, but also for their adverse side effects, e.g. weight gain and osteoporosis. GCs act through the glucocorticoid receptor (GR), a member of the superfamily of nuclear receptors (reviewed in Griekspoor et al., 2007). In the absence of ligand, GR is retained in the cytosol as part of a chaperone-containing multiprotein complex, which maintains a high affinity for the ligand. Upon hormone binding, GR translocates to the nucleus, where it acts as a transcription factor (TF). The GR subunits homodimerize and bind DNA at Glucocorticoid Response Elements (GREs) in the vicinity of target genes (reviewed in Schoneveld et al., 2004). GRE-bound GR recruits multiple transcriptional co-activator complexes, which stimulate transcription (reviewed in Jenkins et al., 2001; Schaaf and Cidlowski, 2002). The aforementioned properties of GR are reflected by its modular structure (Fig. 1A). The central domain contains two zinc fingers providing a dimerization interface as well as the DNA binding domain (DBD). The C-terminal ligand-binding domain (LBD) is responsible for high affinity binding of GCs. The LBD overlaps with the activation domain AF2 (activation domain 2), which is exposed after a conformational change induced by ligand binding. The exposed AF2 mediates the interaction with co-activators. The N-terminal part of the receptor contains 
AF1, a ligand-independent activation function, required for transcriptional enhancement through the recruitment of co-activators, and association with basal transcription factors.

The trans-activation function of GR cannot solely account for the numerous physiologic effects of GCs. GR also controls many cellular processes by influencing multiple pathways in a trans-activation independent manner. In particular, GR modulates, positively or negatively, the trans-activation function of other TFs. The modulation may also function the other way around, GR transcriptional activity being potentiated or inhibited by another TF. The regulation can be either indirect, resulting from an interference with upstream signaling pathways regulating the activation of TFs, or can result from a direct mutual regulation of GR and the other TF at the promoter of the target gene. For the purpose of this review, the mutual regulation of other TFs by GR and of GR by other TFs will be referred to as "crosstalk". We will here use selected examples to discuss the molecular mechanisms of the crosstalk between GR and other TFs.

\section{Indirect crosstalk with transcription factors: interference with signaling pathways}

GR can interfere with signal transduction along several pathways, for instance those affecting the MAP kinases Erk, p38, JNK and the canonical Wnt pathway. The activity of the extracellular regulated kinases (Erk)-1 and -2 and of the MAP-kinase p38 is inhibited by GCs (Rider et al., 1996; Hulley et al., 1998; Lasa et al., 2001). The inhibition of Erk$1 / 2$ and p38 by GR requires de novo protein expression exerted via the classical transactivation function of GR (Kassel et al., 2001; Lasa et al., 2001). GR induces the expression of MAP kinase phosphatase-1 (MKP-1), presumably via the binding of GR to 
putative GREs in regulatory regions of the $m k p-1$ promoter. The resulting increase in the level of MKP-1 is responsible for the dephosphorylation and thus inactivation of activated Erk-1/2 and p38 (Kassel et al., 2001; Imasato et al., 2002; Lasa et al., 2002). Reduced signaling through Erk-1/2 and p38 and dependent kinases also reduces the activation of downstream TFs, e.g. Elk-1 or AP-1 (reviewed in Davis, 1995; Shi and Gaestel, 2002). Thus, the inhibition of these MAP kinases by GR could contribute to the repression of gene expression by these TFs.

In contrast to the interferences with Erk-1/2 and p38, negative regulation by GCs of c-Jun $\mathrm{N}$-terminal kinase (JNK) appears to occur within less than a minute which led to the suggestion of a mechanism different from that inhibiting Erk or p38 (Caelles et al., 1997; Swantek et al., 1997; Hirasawa et al., 1998). Indeed, the inhibition did not require de novo protein expression (Caelles et al., 1997). Furthermore, the GR mutant $\mathrm{GR}_{\mathrm{A} 458 \mathrm{~T}}$ (GRdim), which fails to dimerize, to bind DNA and to trans-activate efficiently (Heck et al., 1994), inhibited JNK activity as well as wild type GR (Gonzalez et al., 2000). This result, together with the rapidity of the effect of GCs on the activity of JNK, clearly speaks for an unconventional, non-genomic mechanism of JNK inhibition. In support of this hypothesis, GC-induced GR directly interacted with JNK (Bruna et al., 2003). The interaction was mapped to a JNK docking site in the GR LBD. Mutation of critical residues in the docking motif abrogated the hormone-dependent interaction with JNK and the inhibition of JNK activity by GCs (Bruna et al., 2003). Since the inhibition of JNK activity by GCs is also reflected by a decrease in the phosphorylation of c-Jun, this mechanism is another candidate for the repression of AP-1 function by GCs (Caelles et al., 1997). 
GCs-mediated inhibition of Wnt dependent transcription has been suggested to occur by interference with signal transduction (Ohnaka et al., 2005; Smith and Frenkel, 2005). In the canonical Wnt pathway (reviewed in Novak and Dedhar, 1999; Arce et al., 2006), the ligand Wnt binds to its surface receptor Frizzled. In the absence of ligand, the pathway is actively repressed by the serine/threonine kinase glycogen synthase kinase 3 beta (GSK3 $\beta$ ), which phosphorylates and promotes the degradation of $\beta$-catenin. Upon Wnt binding to Frizzled, Dishevelled is activated and prevents the phosphorylation and degradation of $\beta$-catenin. $\beta$-catenin thus accumulates and translocates to the nucleus where it associates with TFs from the lymphoid enhancer factor (LEF)/T-cell factor (Tcf) family to form an active TF. GCs were shown to decrease the levels of $\beta$-catenin and inhibit LEF/Tcf transcriptional activity (Ohnaka et al., 2005; Smith and Frenkel, 2005). An indirect mechanism has been proposed: GC-dependent inhibition of phosphatidylinositol 3-kinase (PI3K)/Akt and therefore reduction of the phosphorylation of GSK3$\beta$ by Akt, resulting in increased GSK3 $\beta$ activity and thus decreased $\beta$-catenin levels (Smith and Frenkel, 2005).

Another report suggests a different mechanism for the GC-mediated repression of LEF/Tcf transcriptional activity (Ohnaka et al., 2005). Here, the repression was also associated with a decrease in the levels and nuclear translocation of $\beta$-catenin, but independently of GSK3 $\beta$ regulation. The authors proposed that GCs induce the transcription of dickkopf-1 (Dkk-1), a secreted antagonist of Wnt signaling, presumably through binding of GR to putative GREs in the $d k k-1$ promoter (Ohnaka et al., 2004). Treatment of cells with an anti-Dkk-1 antibody partially suppressed the GC-dependent inhibition of Wnt3a-induced LEF/Tcf transcriptional activity (Ohnaka et al., 2005). A 
discrimination between the two hypotheses should be possible by inhibiting protein synthesis.

\section{Direct crosstalk with transcription factors.}

Apart from these indirect mechanisms by which GCs might interfere with the activities of other TFs, GR is involved in direct crosstalk with other TFs. Here, the GR and the other TF directly affect each other at the promoter of their respective target genes. Very often the modulation is bidirectional: GR affects the transcriptional function of the other TF, and the other TF affects the transcriptional function of GR. The transcriptional result of the crosstalk depends on the TF, on the target DNA regulatory element and possibly other factors: it can be either positive with an increased transcriptional activation, or negative leading to transcriptional repression. Three main modes of modulation can be distinguished by the nature of the target regulatory element: regulation at so-called composite response elements, at overlapping response elements, or at response elements without binding sites for the modulating TF (Fig. 2).

\section{Crosstalk at composite response elements}

Composite response elements bind both GR and the other TF (Fig. 2A). Here the crosstalk can be positive or negative. For example, GR and the octamer-binding TF Oct-1 synergistically activate the mouse mammary tumor virus (MMTV) promoter (Miksicek et al., 1987). This synergism is due to a cooperative DNA binding of GR to the GRE and Oct-1 to an octamer sequence in the long terminal repeat (LTR) sequence of MMTV (Bruggemeier et al., 1991). The DNA binding of Oct-1 strictly depends on GR binding, and Oct-1 binding is required for the transcriptional induction by GR (Bruggemeier et al., 
1991). This synergism can be recapitulated using an artificial reporter construct containing only a GRE and an octamer sequence (Wieland et al., 1991), thus is apparently not a matter of chromatin structure but rather due to direct interaction between the two factors. Similarly, at the somatostatin and phosphoenolpyruvate carboxykinase (PEPCK) genes, GR and the cAMP response element (CRE) binding protein (CREB) positively and mutually influence each others binding to GRE and CRE elements, respectively (Imai et al., 1993; Liu et al., 1994). In the positive crosstalk at composite elements, the modulating TF, though binding DNA, does not necessarily induce transcription by itself. For example, the GR-inducible tyrosine aminotransferase (TAT) promoter has binding sites for TFs of the Ets family. Ets1 itself does not activate the promoter, but, through binding to the Ets element, strongly increases the induction by GR (Espinas et al., 1994). Another interesting case of positive crosstalk between GR and the signal transducer and activator of transcription (STAT) 5 will be discussed later, since the crosstalk involves either a composite response element, or a mechanism independent of GR DNA binding.

Crosstalk at composite elements can also result in transcriptional repression (Fig. 2A). For instance, GR represses the CCAAT/enhancer binding protein beta (C/EBP)-mediated induction of the Glutathione S-transferase (GST) A2 gene, via the binding of GR to a GRE-like sequence and the subsequent recruitment of the transcriptional co-repressor Silencing Mediator of Retinoic acid and Thyroid hormone receptors (SMRT) (Ki et al., 2005). The mouse proliferin gene carries a composite response element, which binds GR and AP-1 (Diamond et al., 1990). Here, the result of the crosstalk depends on the subunit composition of the dimeric AP-1 TF. The transcriptional activation by c-Jun homodimers 
is enhanced by the binding of GR, whereas the activation by c-Jun/c-Fos heterodimers is repressed (Diamond et al., 1990).

\section{Crosstalk at overlapping response elements}

In the second mode of interference, GR blocks transcription through the binding to overlapping response elements (Fig. 2B). In this mode of action, GR DNA binding hampers the binding of another TF to its site. A classical example of such a crosstalk is the negative regulation of the osteocalcin gene by GCs. At this gene, the GRE overlaps with the TATA box, and GR prevents the binding of the general transcription factor IID resulting in repression of transcription (Strömstedt et al., 1991). Transcription of the prolactin gene was reported to be negatively regulated by GR through binding to a socalled "negative GRE" (Sakai et al., 1988). It was later shown that this GR binding site overlaps with those for the TFs Oct-1 and pre-B-cell leukemia homeobox (Pbx), and that GR DNA binding blocks the binding of these TFs (Subramaniam et al., 1998). In another reported example of overlapping binding sites GR-mediated repression of the glycoprotein hormone $\alpha$-subunit gene was proposed to occur by a putative GRE blocking the binding of CREB to a CRE in the promoter (Akerblom et al., 1988). This hypothesis was however discarded, when it was shown that the DNA binding by GR was not required for this repression (Chatterjee et al., 1991; Stauber et al., 1992).

\section{Crosstalk at response elements without binding sites for the modulating TF}

In the third mode of interference, the crosstalk between GR and the other TF occurs at response elements without binding sites for the modulating factor (GR or the other TF, Fig. 2C or 2D). This crosstalk results in a repression in the vast majority of cases, and was therefore termed trans-repression. Most of our knowledge concerning this mode of 
crosstalk comes from the study of the trans-repression by GR of the TFs AP-1 (Jonat et al., 1990; Schüle et al., 1990; Yang-Yen et al., 1990) and NF-кB (Mukaida et al., 1994; Ray and Prefontaine, 1994; Scheinman et al., 1995). The early finding that the negative crosstalk between GR and AP-1 was mutual, raised one of the first questions on the

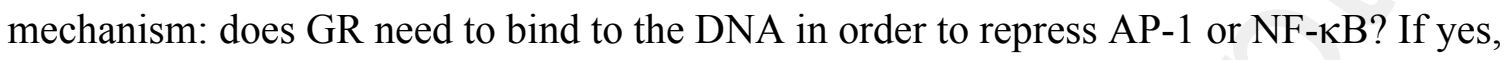
it would need to be at non-consensus GREs, since most of the GR-repressed AP-1 and $\mathrm{NF}-\kappa \mathrm{B}$ target genes do not carry GREs in their regulatory regions. The putative nonconsensus GRE cannot be the AP-1 binding element itself as GR cannot bind consensus AP-1 binding sites (Karin et al., 1984). Nevertheless GR represses transcription from minimal reporter constructs containing only AP-1 binding motifs (Jonat et al., 1990; Schüle et al., 1990; Yang-Yen et al., 1990). Similarly, GR interferes with other TFs at minimal reporter constructs containing only the response element for the TF (Fig. 2C). This is the case for NF-кB (Mukaida et al., 1994; Ray and Prefontaine, 1994; Scheinman et al., 1995), for the Ets-related TF PU.1/Spi-1(Gauthier et al., 1993), Sma- and Madrelated proteins (Smad)3 and 4 (Song et al., 1999), the lymphocyte T helper 1 -specific TF T-bet (Liberman et al., 2007), Oct-1/2 (Wieland et al., 1991; Kutoh et al., 1992), STAT6 (Biola et al., 2000), and for the interferon (IFN) regulatory factor 3 (IRF3) (Reily et al., 2006). Conversely, GR-mediated transcription is repressed by other TFs at promoters containing only GREs, but no binding site for the repressing TF (Fig. 2 D), e.g. AP-1 (Lucibello et al., 1990; Schüle et al., 1990), NF-кB (Ray and Prefontaine, 1994; Scheinman et al., 1995), STAT5 (Stöcklin et al., 1996), PU.1/Spi-1 (Gauthier et al., 1993), the orphan nuclear receptor Chicken Ovalbumin Upstream Promoter-Transcription 
Factor II (COUP-TFII) (de Martino et al., 2004), Smad6 (Ichijo et al., 2005), or T-bet (Liberman et al., 2007).

In rare cases this third mode of crosstalk can result in synergy. GR potentiates COUPTFII-mediated activation of a promoter containing only COUP-TFII response elements (de Martino et al., 2004), and STAT5 response elements are sufficient for GR synergy with STAT5 transcriptional activity (Stoecklin et al., 1997). In the reverse situation, GREs suffice for the increase of GR-mediated transcription by Oct-1/2 (Wieland et al., 1991).

These observations suggest that GR interferes with other TFs without binding to DNA. However, some controversy was introduced by reports studying the contribution of the DNA binding domain (DBD) of GR in the crosstalk. Most of these studies concern the trans-repression of AP-1 and NF- $\kappa$ B. Deletion of the $\mathrm{GR}_{\mathrm{DBD}}$ abolished the repression of AP-1 (Schüle et al., 1990; Yang-Yen et al., 1990) and of NF- אB (McKay and Cidlowski, 1998; Scheinman et al., 1995). Both Zn fingers of the DBD seem required, since the deletion of either, or a point mutation in the first coordinating Cys of either $\mathrm{Zn}$ finger abolished the repression of the NF- $\kappa \mathrm{B}$-dependent interleukin (IL)-6 promoter (Ray et al., 1991). Similarly, a point mutation in the first coordinating Cys of the first $\mathrm{Zn}$ finger (C421G) abolished the repression of AP-1 (Yang-Yen et al., 1990). The mutant GRs $\Delta 428-490$ and $\Delta 380-465$, with partial deletion in the $\mathrm{GR}_{\mathrm{DBD}}$, could only partially repress AP-1 (Jonat et al., 1990). The critical role of the $\mathrm{GR}_{\mathrm{DBD}}$ in the trans-repression was confirmed by the use of point mutations that abolished the repression (Fig. 3). For instance, $\mathrm{GR}_{\mathrm{K} 442 \mathrm{G}}$ (Lucibello et al., 1990), GR $\mathrm{F}_{\mathrm{F} 63 \mathrm{~S}}$ and $\mathrm{GR}_{\mathrm{S} 444 \mathrm{P}}$ (Yang-Yen et al., 1990), 
$\mathrm{GR}_{\mathrm{R} 488 \mathrm{Q}}$ and $\mathrm{GR}_{\mathrm{K} 490 \mathrm{E}}$ in the rat GR (corresponding to R469 and K471 in hGR) (Liden et al., 1997), GR S425G, $\mathrm{GR}_{\mathrm{Y} 478 \mathrm{~L} / \mathrm{R} 479 \mathrm{G}}$ and $\mathrm{GR}_{\mathrm{L} 436 \mathrm{~V}}($ Heck et al., 1994) were not able to repress AP-1 and/or NF- $\kappa \mathrm{B}$. The $\mathrm{GR}_{\mathrm{DBD}}$ is also required for the crosstalk with other TFs. T-bet was not repressed by $\mathrm{GR}_{\mathrm{S} 425 \mathrm{G}}$ (Liberman et al., 2007), or $\mathrm{GR}_{\triangle \mathrm{DBD}}, \mathrm{GR}_{\mathrm{S} 444 \mathrm{P}}$ and $\mathrm{GR}_{\mathrm{F} 463 \mathrm{~S}}$ in the rat GR (S425 and F444 in hGR) did not repress the orphan nuclear receptor NGFI-B/NuR77 mediated activation of the proopiomelanocortin (POMC) promoter (Philips et al., 1997; Martens et al., 2005).

Although these observations seemed to indicate a role of DNA binding in the crosstalk, other mutations within the $\mathrm{GR}_{\mathrm{DBD}}$ did not interfere with the crosstalk ability of GR (Fig. 3). The LS7 mutation in the rat $\mathrm{GR}_{\mathrm{DBD}}(\mathrm{P} 493 \mathrm{R}$ and $\mathrm{A} 494 \mathrm{~S}$, corresponding to $\mathrm{P} 474$ and A475 in hGR) although not affecting the DNA binding of GR to a GRE, strongly inhibited trans-activation (Schena et al., 1989), but did not affect the GR-mediated repression of AP-1 (Yang-Yen et al., 1990), NF-кB (Heck et al., 1997; Liden et al., 1997), or NGFI-B/NuR77 (Philips et al., 1997). More informative are the mutations in the dimerization interface of GR. A prerequisite for efficient GR DNA binding and transactivation is its homodimerization which is mediated by the D-loop of the DBD (Umesono and Evans, 1989; Dahlman-Wright et al., 1991). The so-called dim (A458T) and D4X mutations (N454D, A458T, R460D, D462C) in the D-loop strongly inhibited GR dimerization and GR-mediated trans-activation, but did not eliminate the repression of AP-1 (Heck et al., 1994), NF-אB (Heck et al., 1997; Liden et al., 1997), NGFI-B /NuR77 (Martens et al., 2005), Smad3 and 4 (Song et al., 1999) or T-bet (Liberman et al., 2007). These results clearly show that GR DNA binding is not required for this kind of 
crosstalk. Relevant residues in the DBD may however be important for protein-protein interactions taking part in the crosstalk (see below).

Divergent results have been reported for the synergism between GR and STAT5 at the $\beta$ casein promoter. The STAT5 binding sites of this promoter were sufficient for enhanced transcription upon GC treatment, and the dimerization-deficient D4X GR mutant functioned synergistically with STAT5 (Stoecklin et al., 1997), suggesting that no DNA binding by GR is required for this crosstalk. Another report published in the same year suggested the opposite, by showing that GR was binding to GRE half-sites in the $\beta$ casein promoter, and that these sites were required for the synergism between GR and STAT5 (Lechner et al., 1997). The crosstalk between GR and STAT5 would then be another case of crosstalk at composite regulatory elements. It was later shown that both mechanisms were used for this crosstalk, depending on the level of activated GR. At low GR levels, the DNA binding was required, presumably to the GRE half-sites, whereas at high GR levels, GR DNA binding was dispensable (Doppler et al., 2001).

\section{Protein-protein interaction}

If GR can interfere with the transcriptional function of other TFs without binding to DNA, it most likely has to physically interact, directly or indirectly, with these TFs.

In co-immunoprecipitation experiments after crosslinking, GR could be detected in a complex with both c-Jun and c-Fos (Jonat et al., 1990; Yang-Yen et al., 1990; Touray et al., 1991). c-Fos appeared to be essential for the interaction since after anti-sense mediated downregulation of c-Fos expression the complex of GR and c-Jun could not be detected (Touray et al., 1991). This suggests that c-Fos, and not c-Jun, directly or 
indirectly interacts with GR and that perhaps c-Fos is the primary target of GR action in its direct crosstalk with AP-1. This hypothesis is in accordance with results of in vitro transcription experiments showing that c-Fos is the primary target for GR in the repression of AP-1 (Kerppola et al., 1993).

Physical interactions could also be detected by co-immunoprecipitation and/or GSTpulldown experiments of GR and other TFs regulated by GR, such as the RelA/p65 NFкB subunit (Caldenhoven et al., 1995; Scheinman et al., 1995), STAT5 (Stöcklin et al., 1996), Oct-1/2 (Kutoh et al., 1992), CREB (Imai et al., 1993), Smad3 (Song et al., 1999) and Smad6 (Ichijo et al., 2005), Ets2 (Mullick et al., 2001), NGFI-B/NuR77 (Martens et al., 2005), or T-bet (Liberman et al., 2007).

If these interactions between GR and TFs were indeed relevant for the crosstalk, the GR point mutants described above may not be co-precipitable with these TFs. Some of the mutations affecting the crosstalk were in the GR $\mathrm{DBD}$. A simple hypothesis would be that the $\mathrm{GR}_{\mathrm{DBD}}$ forms the interaction interface needed for the complex formation with the other TF. Several data have been reported which support this hypothesis. The GR

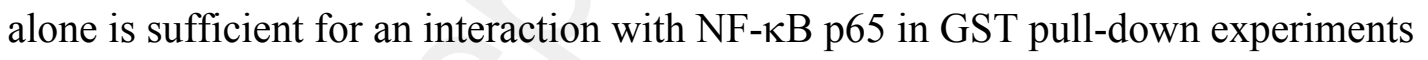
(Nissen and Yamamoto, 2000; Garside et al., 2004; Ogawa et al., 2005). Although the $\mathrm{GR}_{\mathrm{DBD}}$ alone was not able to repress NF- $\kappa \mathrm{B}$-dependent transcription, the $\mathrm{GR}_{\mathrm{DBD}}$ fused to the transcriptional repressor domain of Mad1 repressed NF- $\kappa \mathrm{B}-$ dependent transcription (Nissen and Yamamoto, 2000). This result suggests that the $\mathrm{GR}_{\mathrm{DBD}}-\mathrm{p} 65$ interaction is functional and occurs at $\kappa \mathrm{B}$ response elements. The observation that $\mathrm{GR}_{\mathrm{K} 471 \mathrm{~A}}$, mutated in its DBD and unable to repress NF-אB (Liden et al., 1997), does not interact with p65 
(Ogawa et al., 2005) provides further support for a role of the $\mathrm{GR}_{\mathrm{DBD}}-\mathrm{p} 65$ interaction in the negative crosstalk between GR and NF- $\kappa \mathrm{B}$.

The $\mathrm{GR}_{\mathrm{DBD}}$ is also sufficient for the physical interaction between GR and other TFs it interferes with, such as Ets2 (Mullick et al., 2001), NGFI-B/NuR77(Martens et al., 2005), Oct-1 and -2 (Prefontaine et al., 1998). The DBD mutant GR $_{\mathrm{S} 425 \mathrm{G}}$, does not interact with T-bet, and does not repress T-bet-dependent transcription (Liberman et al., 2007), suggesting that an interaction between the $\mathrm{GR}_{\mathrm{DBD}}$ and T-bet is essential for the GRmediated repression of T-bet transcriptional activity.

In summary, the requirement for the $\mathrm{GR}_{\mathrm{DBD}}$ in the crosstalk might reflect the requirement for a physical interaction either between GR and the modulated TF directly or with other proteins required for the crosstalk.

\section{Interference with DNA binding}

Given that in the negative crosstalk GR and the modulated TF participate in a physically interacting complex and that the "interfering" TF does not bind DNA, we now need to ask how repression is accomplished. One simple explanation of the transcriptional inhibition might be that the physical interaction prevents the binding of the repressed TF to DNA. This hypothesis was supported in the early reports of GR-mediated repression of AP-1 activity, where GR decreased the binding of c-Jun to DNA, and, conversely, c-Jun decreased the binding of GR to DNA in electrophoretic migration shift assays (EMSA) (Schüle et al., 1990; Yang-Yen et al., 1990). However, at the same time, a contradictory report showed that GR did not decrease c-Jun/c-Fos DNA binding in EMSA (Jonat et al., 1990). In vivo footprinting experiments confirmed that GCs do not alter occupancy of the 
AP-1 site at the collagenase-1 (MMP-1) promoter (König et al., 1992). Since then, we and others confirmed more directly, by chromatin immunoprecipitation (ChIP), that GR does not decrease the recruitment of c-Fos and c-Jun at the promoter of the GR-repressed AP-1 target genes collagenase-1 (Kassel et al., 2004) and collagenase-3 (Rogatsky et al., 2002). Since the ChIP experiments reflect better the true in vivo situation, they more credibly support that interference with DNA binding is not the crosstalk mechanism.

Very similar observations were made concerning the repression of NF- $\kappa$ B by GR. Results of EMSA suggested that GR inhibits (Mukaida et al., 1994; Scheinman et al., 1995), or does not inhibit (De Bosscher et al., 1997) the DNA binding of NF- $\kappa$ B. ChIP experiments, however, clearly demonstrated that GR does not decrease the recruitment of NF- $\kappa \mathrm{B}$ to the promoter of IL-8 and intracellular adhesion molecule (ICAM) genes, two different NF- $\mathrm{B}$ target genes repressed by GCs (Garside et al., 2004; Kassel et al., 2004; Luecke and Yamamoto, 2005; Nissen and Yamamoto, 2000; Ogawa et al., 2005). Surprisingly, at the eotaxin promoter, which is also repressed by GR, GC treatment

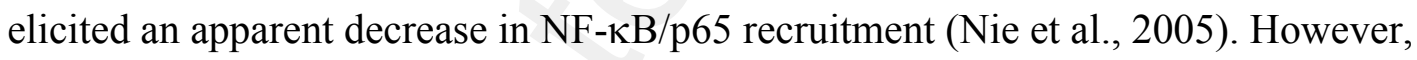
caution in the interpretation of the result is appropriate. An anti-p65 antibody recognizing an epitope different from that in the other reports was used in this study. It is possible that the GC treatment modified the structure of the protein complex recruited to the promoter in such a way that the p65 epitope was masked, falsely indicating a decrease in p65 recruitment.

Similar observations were made in the crosstalk between GR and other TFs. Based on ChIP experiments the GR-modulated TF IRF3 (Ogawa et al., 2005; Reily et al., 2006) 
was still recruited to the IFN-stimulated response element (ISRE) from the interferoninduced protein with tetratricopeptide repeats (Ifit)1 gene promoter under conditions of repression by GR (Ogawa et al., 2005). Similarly, during GR-mediated repression of NGFI-B/NuR77-induced POMC transcription, NGFI-B/NuR77 was still recruited to the promoter (Bilodeau et al., 2006).

A similar situation is observed in the reverse crosstalk, when GR transcriptional activity at GRE containing promoters is repressed by other TFs. For instance, ChIP experiments have clearly established that GR is still recruited to chromatin at the promoter of GR target genes when it is repressed by p65 (Burkhart et al., 2005), by STAT5 (Biola et al., 2001) or by Smad6 (Ichijo et al., 2005).

\section{Tethering}

Concluding that the repressing TF does not decrease the binding of the repressed TF to its cognate response element, and that the interference requires a protein-protein interaction between the two TFs, demands that the interaction occurs on DNA, at the response element. This hypothesis of a tethering of the repressing TF to the promoter together with the repressed TF has been supported by several experiments. GR was recruited in ChIP experiments to the AP-1-dependent collagenase-3 promoter under conditions of GCmediated repression (Rogatsky et al., 2001). In successive “double ChIP” experiments GR and AP-1 were indeed recruited together to one and the same collagenase-1 promoter element under repressing conditions (Kassel et al., 2004). Similarly, in repressing condition, GR was recruited to the $\kappa \mathrm{B}$ binding site of the IL-8 promoter (Kassel et al., 2004; Garside et al., 2004; Luecke and Yamamoto, 2005). 
The tethering hypothesis was also confirmed in cases of repression by other TFs of GR transcriptional activity at GRE-containing promoters. For instance, the GR-repressing TFs p65 (Burkhart et al., 2005), COUP-TFII (de Martino et al., 2004), Smad6 (Ichijo et al., 2005) were recruited, in a GC-dependent manner, to repressed GRE-containing promoters.

In the study of more complex promoters it is not always clear which TF in a multiprotein enhanceosome is the tethering partner during crosstalk. As an example, the $\alpha 2-$ macroglobulin gene is synergistically induced by STAT3 (upon IL-6 stimulation) and by GR (Takeda et al., 1998; Lerner et al., 2003). Upon IL-6 stimulation, STAT3 was recruited to the enhanceosome, and STAT3 alone sufficed to induce a low level of transcriptional activation. GC treatment promoted the recruitment of GR to the enhancer, but did not activate transcription. The observation that purified GR did not bind the enhancer DNA in EMSA suggests that GR was recruited to chromatin via a tethering mechanism. However, GR tethering occurred without co-stimulation with IL-6 and in the absence of STAT3. Thus, the tethering probably occurred via other enhancer-bound proteins. In addition to the STAT binding site the enhancer contains binding sites for AP1 and Oct-1, which are constitutively occupied by c-Jun and Oct-1. These sites were necessary to promote a full induction by IL-6 and GC, but were not sufficient to promote the synergism between GR and STAT3. The authors propose a model in which IL-6 induces the recruitment of STAT3 to its elements and GC treatment promotes the tethering of GR to chromatin via an interaction with enhancer-bound AP-1 and/or Oct-1 (Lerner et al., 2003). 
The ChIP experiments mentioned above do not prove a direct TF-GR interaction. Rather additional partner proteins could be involved in the tethering of GR. Even at simple regulatory elements the mere protein-protein interaction between the 2 interfering TFs might not suffice for the tethering of the regulating TF, at least in the case of GRmediated repression of AP-1- and NF- $\kappa \mathrm{B}$. We have identified nTrip6, a nuclear isoform of the LIM domain-containing focal adhesion protein Trip6, as essential for the tethering of GR to repressed AP-1- and NF- $\mathrm{B}$-regulated promoters (Kassel et al., 2004). nTrip6 physically interacts with both GR and AP-1 or NF- $\kappa$ B. Reducing the level of nTrip6 by RNA interference or abolishing its interaction with GR by dominant-negative mutations of Trip6 eliminated GR-mediated repression of AP-1- and NF- $\kappa \mathrm{B}$, showing that nTrip6 is an essential component of the crosstalk. Moreover, decreasing the levels of nTrip6 reduced the tethering of GR to the repressed AP-1-dependent collagenase-1 promoter, without affecting AP-1 occupancy (Kassel et al., 2004). These results show that nTrip6, via its interaction with both TFs, forms an essential platform for the stable recruitment of GR to the AP-1- or NF- $\mathrm{BB}$-bound promoter. This suggests at the same time that the previously reported complex formation was not based on direct interaction between GR and AP-1 or NF- $\mathrm{AB}$, but rather was mediated by nTrip6. nTrip6 is a new kind of transcriptional regulator, functioning as a tethering factor in the crosstalk between different TFs. Are such tethering factors also required for the crosstalk between GR and TFs other than AP-1 and NF- $\mathrm{BB}$ ? Other LIM domain-containing proteins do function as transcription co-factors (reviewed in Bach, 2000; Kadrmas and Beckerle, 2004). For instance, Hic5/Ara55 regulates transcription mediated by both GR (Yang et al., 2000), and TFs of the LEF/Tcf family (Ghogomu et al., 2006). Moreover, overexpression of 
Hic5 increased the repression of GR-mediated transcription by LEF/Tcf, suggesting that Hic5 might play a role in this crosstalk (Ghogomu et al., 2006). Whether Hic5 mediates the tethering of LEF/Tcf to the GR-bound promoter remains to be determined.

What is the molecular mechanism of interference in the crosstalk between GR and other TFs? In the case of the positive crosstalk, GR stimulates transcriptional activity without the need to bind DNA itself, but tethered to the modulated TF. This property matches typically the definition of a transcriptional co-activator. Co-activators exert their action via activation functions or domains. Thus, in the synergistic crosstalk GR may supply the activation domains. This was indeed shown for the positive crosstalk between GR and COUP-TFII (de Martino et al., 2004). The transcriptional activity of COUP-TFII was increased by GR, but not by a GR deletion mutant still interacting with COUP-TFII but lacking the ligand-dependent activating function (LBD/AF2) (de Martino et al., 2004). Similarly, GR acts as a co-activator for STAT5, presumably via its LBD/AF2 domain (Doppler et al., 2001).

Things are not that simple in the case of the negative crosstalk. Here a TF, with its own activator domain(s), is tethered to a promoter bound by another TF. Yet, the recruitment of a transcriptional activator does not further enhance transcription, but rather represses it. How is the transcriptional activity of the repressing TF silenced, and how does it suppress the activity of the regulated TF at the promoter of its target genes? Several hypotheses have been put forward and will be discussed in the following paragraphs.

\section{Involvement of transcriptional co-activators in trans-repression}

Loss of transcriptional co-activator recruitment 
The repressed TF is still recruited to the target promoter, and yet is not able to stimulate transcription. Since TFs exert their function through the recruitment of transcriptional coactivators, maybe they are unable to recruit an essential co-activator when repressed.

Particular attention has been given to the CREB binding protein (CBP)/p300 and to the steroid receptor co-activator 1 (Src-1). CBP can apparently function as co-activator for a number of TFs including AP-1 (Arias et al., 1994; Kwok et al., 1994), NF-кB (Perkins et al., 1997) and GR (Kamei et al., 1996). Similarly, Src-1 can apparently act as a common co-activator for AP-1 (Lee et al., 1998), NF-кB (Na et al., 1998) and GR (Onate et al., 1995). The hypothesis has been put forward that the mutual repression between AP-1, $\mathrm{NF}-\kappa \mathrm{B}$ and GR might result from a competition for limiting amounts of these coactivators in the cell (Kamei et al., 1996; Sheppard et al., 1998). One problem with this hypothesis is the question of specificity. Numerous other TFs use CBP/p300 and/or Src-1 as essential co-activator, yet they are not repressed by GR, nor do they repress GR. Moreover, if the model held true, over-expressing the co-activator should overcome its limited availability, and the negative crosstalk should be abolished. This is not the case. The repression by GR of NF- $\mathrm{KB}$ - and AP-1-dependent transcription, and the repression by NF- $\kappa \mathrm{B}$ of GR-mediated transcription were not affected by over-expression of CBP/p300 and Src-1 (De Bosscher et al., 2000; McKay and Cidlowski, 2000; De Bosscher et al., 2001). Similarly, CBP/p300 and Src-1 are co-activators for STAT5, and their over-expression did not alleviate STAT5-mediated repression of GR-dependent transcription (Pfitzner et al., 1998; Biola et al., 2001). 
However, one might argue that in these studies the level of over-expression might not have been sufficient to compensate the limited availability of the co-activators. Let us phrase the question differently: does the ability of GR to trans-repress AP-1 and NF- $\mathrm{kB}$ depend on its ability to interact with co-activators? The recruitment of co-activators to the GR AF2 domain is induced by the binding of the ligand. Different synthetic GR ligands differ in their ability to activate GR-dependent transcription and to trans-repress AP-1 and NF-KB. Notably, the so-called "dissociated" ligands or selective glucocorticoid receptor agonists (SEGRAs) have a reduced capacity to induce transcription while maintaining GR-mediated repression (reviewed in Miner, 2002; Schäcke et al., 2006). Since the ability to induce transcription depends on the ligand-induced interaction with co-activators, one might postulate that the reduced transcriptional activation by the dissociated compound should indicate an impaired recruitment of co-activators. This hypothesis has to our knowledge not been investigated for most of the GR ligands. However, one ligand, the AL-438 compound, showed an altered trans-activation profile. This ligand was able to activate only a subset of GR target genes (Coghlan et al., 2003). This alteration was attributed to a different co-activator recruitment in response to AL438 as compared to the reference GC prednisolone. Yet AL-438 is a "dissociated" ligand in that it repressed NF- $\mathrm{KB}$-dependent gene expression as potently as prednisolone (Coghlan et al., 2003). These observations suggest that GR-mediated repression is independent of its ability to interact with at least some co-activators.

A more direct way of addressing the question - competition for a co-activator - would be to specifically abrogate the co-activator interaction of either the repressed TF or the repressing TF. An NF-kB/p65 mutant not interacting with CBP was still able to activate 
transcription of a GAL4-regulated reporter gene when fused to the GAL4 DNA binding domain, and was still repressed by GR (De Bosscher et al., 2000). Similarly, a STAT5 deletion mutant not interacting with CBP was still able to repress GR-mediated transcription (Pfitzner et al., 1998). The effect of mutations in the LBD/AF2 domain of GR might also help clarifying the role of co-activator interaction (Fig. 4). The substitution mutation Y735V in the ligand binding pocket of GR did not modify the affinity for the ligand but strongly decreased the interaction with Src-1 and therefore abolished GR-mediated trans-activation (Ray et al., 1999; Stevens et al., 2003). However,

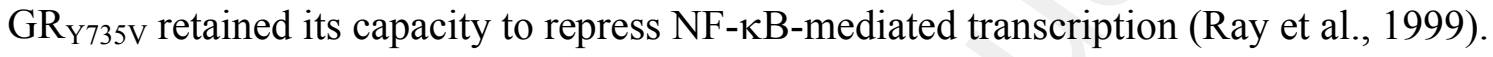
The residue E755 (E773 in rat GR) in helix 12 of the GR ligand binding domain is part of a charge clamp that forms an essential ligand-dependent interaction interface with the conserved LxxLL motifs (Savkur and Burris, 2004) of multiple co-activators (Bledsoe et al., 2002; Wu et al., 2004). And indeed, mutation of this residue abolishes the interaction with Src-1 (Kucera et al., 2002). However, both the mutants, GR Y755A $_{\text {and }}$ GR $\mathrm{Y}_{755 \mathrm{Q}}$, were still able to repress NF-кB (Wu et al., 2004) and AP-1 (Kassel et al., 2004).

LxxLL motifs-containing co-activators are not the only GR-co-activators (reviewed in Jenkins et al., 2001; Gronemeyer et al., 2004; Griekspoor et al., 2007). Can we exclude the contribution to trans-repression of an interaction between GR and another yet unidentified co-activator? We have deleted the entire AF-1 domain in the AF-2 mutant $\mathrm{GR}_{\mathrm{Y755Q}}$. Using this mutant in a yeast two-hybrid screen (Kassel et al., 2004) did not yield a detectable interaction with any known GR co-activator (unpublished data) and likely also with unknown co-activators. The $\mathrm{GR}_{\triangle \mathrm{AF} 1 \mathrm{mH} 12}$, unable to trans-activate, most likely due to the lack of co-activators recruitment, repressed AP-1-dependent 
transcription (Kassel et al., 2004). These results strongly suggest that GR does not repress AP-1 by sequestering co-activators.

Altogether, results of these different studies clearly show that the crosstalk between GR and $\mathrm{AP}-1$ or NF- $\mathrm{kB}$ does not result from a competition for the binding to common coactivators.

If not competition, the tethered and repressing TF could block the recruitment of a crucial co-activator by the promoter-bound TF. This appears to be the case in the crosstalk between GR and IRF3 (Ogawa et al., 2005; Reily et al., 2006). NF-кB/p65 acts as a signal-dependent co-activator for IRF3. p65 is recruited as a co-activator to IRF3-bound ISRE-containing promoters upon induction with LPS, which activates the Toll-like receptor (TLR)4, but not upon induction with polyinosinic-polycytidylic acid (pI:C) which activates TLR3 (Wietek et al., 2003; Ogawa et al., 2005). GR repressed IRF3dependent transcription of the Iift1 gene only upon stimulation with LPS. Here, GR decreased the recruitment of p65 to the IRF3-bound promoter (Ogawa et al., 2005), suggesting that GR represses IRF3 by hampering the recruitment of the co-activator p65. Conversely, IRF3 is used as a co-activator for a subset of NF- $\kappa \mathrm{B}$ target genes upon induction by LPS (Ogawa et al., 2005). Here again, GR apparently repressed the transcription of these NF- $\mathrm{KB}$ target genes by blocking the recruitment of the co-activator IRF3 (Ogawa et al., 2005). How does this result fit with the observation that GR is tethered to p65 when bound to a promoter? The answer to this question might come from the observation that GR and IRF3 compete for the same binding site on p65, and therefore, the tethering of GR displaces IRF3 from the DNA-bound p65 (Ogawa et al., 
2005). It would be interesting to see whether the activation of IRF3 would alleviate the repression of GR-mediated transcription by $\mathrm{p} 65$.

In an alternative explanation for the repression of IRF3 by GR, GR and IRF3 may compete for the common co-activator GR interacting protein (GRIP)1/Transcription Intermediary Factor (TIF)2/ Nuclear receptor coactivator (NcoA)2, in that overexpression of GRIP1 decreased the GR-mediated repression of IRF3 (Reily et al., 2006). If confirmed, this crosstalk would thus provide an example of a mechanism involving a competition for a common co-activator.

\section{Active role of transcriptional co-activators in trans-repression}

In contrast with the results discussed above, co-activators could even play an active role in trans-repression. CBP overexpression did not prevent the crosstalk between GR and

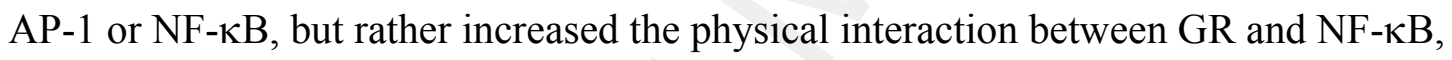
and increased GR-mediated repression of NF-кB (McKay and Cidlowski, 2000). A p65 mutant deficient for the binding to CBP showed a reduced ability to repress GR-mediated transcription (Burkhart et al., 2005). These two reports suggest that CBP plays an active role in the crosstalk between GR and NF- $\kappa \mathrm{B}$. Yet it is not clear whether the co-activation function of $\mathrm{CBP}$ is required per se or whether CBP provides a platform for the interaction with other proteins required for repression.

Along these lines, the p160 family GR co-activator GRIP1 when over-expressed, but not a GRIP1 mutant unable to interact with GR, enhanced the GC-mediated repression of AP-1- and NF-кB-dependent transcription (Rogatsky et al., 2001; 2002; He and Simons, 2007). GRIP1 was recruited together with GR at the AP-1-dependent collagenase-3 
promoter. The overexpression of other p160 co-activators like Src-1 or Rac3/Src-3 did not enhance the repression of AP-1 by GR (Rogatsky et al., 2002). This difference between the co-activators is most likely due to the presence of a specific domain in GRIP1, absent in the other family members, which might act as a repressor domain. The active role of GRIP1 in trans-repression was substantiated by experiments with dominant negative mutants. Overexpression of a GRIP1 construct lacking the repressor domain but still able to interact with GR had a dominant negative effect on the repression of AP-1 and NF- $\kappa B$ by GR (Rogatsky et al., 2001; 2002). If GRIP1 were involved in transrepression, then the SEGRAs showing a reduced capacity to induce transcription while maintaining GR-mediated repression, should still promote the interaction between GR and GRIP1. This was indeed shown with the AL-438 compound, which still mediated an interaction between GR and GRIP1, while reducing GR interaction with the co-activator peroxisome proliferator-activated receptor (PPAR) $\gamma$ coactivator 1 (PGC)-1 (Coghlan et al., 2003). What could be the mechanism which turns a co-activator into a repressor? If CBP were indeed required for repression (see above), does GRIP1 interact with or recruit CBP? This is unlikely, since GRIP1 interacts with CBP through one of its activation domains (Huang and Cheng, 2004), which is dispensable for the co-repressor activity (Rogatsky et al., 2002). GRIP1 might thus act as a bona fide co-repressor in the negative crosstalk. GRIP1 can indeed function as a co-repressor for the TF MyoD (Wu et al., 2005). Alternatively, GRIP1 might mediate the recruitment of a co-repressor, assuming that co-repressors play a role in the negative crosstalk (see below). Supporting the idea that GRIP1 recruits a co-repressor, GRIP1 was recently shown to interact with the histone deacetylase (HDAC)1 (Liu et al., 2006). However the domain of GRIP1 mediating this 
interaction (Liu et al, 2006) does not match the repressor domain required for GRmediated repression (Rogatsky et al., 2002). GRIP1 was recently shown to interact with a new cofactor, STAMP (SRC-1 and TIF2-associated modulatory protein), which might participate in the crosstalk (He and Simons, 2007). Overexpression of STAMP increased GR-mediated repression of AP-1 in a GRIP1-dependent manner, and silencing of STAMP decreased GR-mediated repression of AP-1 (He and Simons, 2007).

The effect of a number of point mutations in the GR LBD/AF-2 might challenge the idea of an involvement of GRIP1 in the crosstalk. For instance, the ligand and DNA binding proficient GR mutants, GR $\mathrm{D}_{441 \mathrm{~V}}$ and $\mathrm{GR}_{\mathrm{V} 729 \mathrm{I}}$, (Hurley et al., 1991; Charmandari et al., 2004) showed an impaired capacity to interact with GRIP1 in in vitro interaction assays (Charmandari et al., 2004), but repressed AP-1- and NF-кB-dependent transcription (de Lange et al., 1997). Similarly, the Val residue 575 was predicted by molecular modeling to make contacts with the LxxLL motifs of co-activators. Accordingly, GR V575A lost its capacity to interact with GRIP1 in GST pull-down assays, but was still able to repress NF- $\kappa$ B-dependent transcription, although less efficiently than $\mathrm{GR}_{\mathrm{wt}}$ (Kunz et al., 2003). The results of these in vitro experiments speak against an involvement of GRIP1 in the crosstalk. However, one cannot exclude the possibility that, in the context of the crosstalk, GR interacts with and mediates the recruitment of GRIP1 via an alternative interaction interface. It would be interesting to study whether the repression-proficient GR mutants impaired in their ability to interact with GRIP1 in vitro are still able to recruit GRIP1 when tethered to AP-1- or NF- $\mathrm{BB}-$ regulated promoters. The study of transrepression after GRIP1 knockdown, or in cells from GRIP1 knockout mice should help clarifying the role of GRIP1 in the crosstalk. 
Our work has shown that nTrip6, interacting with both AP-1 and NF- $\mathrm{KB}$, is recruited to the promoter of their target genes and behaves as a co-activator or co-activator-recruiting factor for both TFs. nTrip6 is also required for GR-mediated repression of AP-1 and NF$\kappa \mathrm{B}$, probably not the co-activator function of nTrip6 per se, but rather its ability to interact with and mediate the tethering of GR to the repressed promoters (Kassel et al., 2004).

Does crosstalk involve the remodeling of chromatin? The SWI/SNF complex is a large multi-protein co-activator complex, recruited to promoters via an interaction with $\mathrm{TF}$, and remodeling nucleosomes in an ATP-dependent manner. The ATPase activity is provided by either Brahma (Brm) or Brm related gene (Brg)1 (reviewed in Martens and Winston, 2003; Simone, 2006). NF-kB/p65-mediated repression of GR-dependent transcription was abolished in a cell line lacking Brg1 and Brm, suggesting that the SWI/SNF complex might be required for this crosstalk (Burkhart et al., 2005). Similarly, the bidirectional negative crosstalk between GR and NGFI-B/NuR77 was abrogated in three different cell lines lacking Brg1 and Brm (Bilodeau et al., 2006). Reconstitution of these cells with either one of the two ATPases restored the crosstalk, confirming that the defect in the crosstalk was due to the lack of a full SWI/SNF complex. The restoration was not observed with ATPase-deficient mutants of Brg1 and Brm, suggesting that the nucleosome remodeling activity of the SWI/SNF complex is required for the crosstalk (Bilodeau et al., 2006). Two interpretations seem possible, either chromatin remodeling catalyzes the recruitment of another protein or protein complex required for repression, or a (e.g.) co-repressor-induced chromatin remodeling through SWI/SNF forms the effector arm of repression. In support of the first interpretation Brg1 was essential for the GR 
dependent recruitment of the co-repressor HDAC2 to the POMC promoter, and to repress the NGFI-B/NuR77-dependent transcription (Bilodeau et al., 2006).

\section{Role of co-repressors or co-repressor complexes}

An attractive hypothesis explaining the mechanism of the negative crosstalk proposes that tethering of the repressing TF mediates the recruitment of a transcriptional corepressor or co-repressor complex. HDACs form a prominent class of co-repressors. Acetylation by co-activators bearing histone acetyltransferase (HAT) activity of critical lysine residues of the N-terminal tails of nucleosomal core histones is usually associated with transcriptional activation. Conversely, the removal of the acetyl residues by HDACs is associated with transcriptional repression (reviewed in Kuo and Allis, 1998; Xu et al., 1999). The putative involvement of HDACs in the negative crosstalk between GR and other TFs is still a matter of debate. The use of chemical inhibitors of HDAC deacetylase activity, like trichostatin A (TSA), gave conflicting results as to their involvement in the negative crosstalk. For instance, TSA was shown to partially reduce the inhibitory effect of GC on IL-1 $\beta$-mediated Granulocyte-macrophage colony-stimulating factor (GM-CSF) release (Ito et al., 2000; Ito et al., 2001), indirectly suggesting that HDACs might be involved in the repression of NF- $\mathrm{B}$ by GR. The same moderate effect on the inhibition GM-CSF release was obtained by silencing HDAC2 expression (Ito et al., 2006), suggesting a role for HDAC2 in the crosstalk. Similarly, the repression by GC of the AP1-dependent induction of the IL-5 promoter was sensitive to TSA treatment (Jee et al., 2005). In line with the suggested involvement of HDACs in the crosstalk between GR and AP-1 or NF- $\kappa \mathrm{B}, \mathrm{GC}$ partially inhibited the IL- $1 \beta$-induced acetylation of lysine $(\mathrm{K}) 8$ 
in histone 4 (H4) (Ito et al., 2000; Ito et al., 2001), and the TNF $\alpha$-induced acetylation of K5 and K12 of H4 at the eotaxin promoter (Nie et al., 2005). However, the observed decreases in acetylation of histone tails do not necessarily reflect the action of an HDAC, but might also result from a lack of acetylation by a HAT. Furthermore, there is so far no evidence that any HDAC is recruited together with GR to an AP-1- or NF- $\kappa$ B-regulated promoter. Finally, other groups failed so far to detect an effect of TSA on the crosstalk between GR and AP-1 or NF-кB (Nissen and Yamamoto, 2000; Van den Berghe et al., 2002).

More convincing data point towards a role of HDAC3 in Smad6-mediated repression of GR (Ichijo et al., 2005). This repression was sensitive to TSA, and Smad6 mediated the co-recruitment of HDAC3 to a GR-bound promoter. Furthermore, Smad6 promoted a decrease in GC-induced acetylation at $\mathrm{H} 3$ and $\mathrm{H} 4$, and a decrease in GRIP1-mediated enhancement of H3 and H4 acetylation (Ichijo et al., 2005). In the crosstalk between GR and NGFI-B/NuR77, the repression by GR of the NGFI-B/NuR77-dependent transcription of POMC was sensitive to HDAC inhibitors, and HDAC2 was recruited to the promoter upon GC treatment. Interestingly, the recruitment of HDAC2 depended on Brg1 (see above), suggesting that GR-induced nucleosomal remodeling might be a prerequisite for the recruitment of co-repressors (Bilodeau et al., 2006).

Another co-repressor, SMRT, may be involved in the repression of GR by COUP-TFII (de Martino et al., 2004). Overexpression of SMRT enhanced the repression by COUPTFII of GR-mediated transcription. A COUP-TFII deletion mutant, interacting with GR but not with SMRT, failed to repress GR dependent transcription (de Martino et al., 
2004). However, there is yet no direct evidence that COUP-TFII mediates the recruitment of SMRT to the GR-bound promoter.

\section{New hypotheses and other ideas}

\section{Inhibition of a de-repression step}

As pointed above, the observed decrease in acetylation of histone tails at AP-1- and NF$\kappa \mathrm{B}$-regulated promoters upon GC treatment does not necessarily reflect the action of an HDAC, but might also result from a lack of acetylation by a HAT. The observation that the treatment with TSA, or the knockdown of HDACs by siRNAs increases both the basal level and the inducibility of NF- $\mathrm{BB}$ target genes (Ashburner et al., 2001; Ito et al., 2001; Pascual et al., 2005; Ito et al., 2006), suggests that in resting conditions these genes are actively repressed by HDACs. Indeed, the activation of NF- $\kappa \mathrm{B}$ target genes involves a de-repression step (Hoberg et al., 2004; 2006). In resting conditions, NF- $\kappa B / p 50$ was constitutively present at the NF- $\kappa \mathrm{B}$ response element of the Inhibitor of apoptosis protein 2 (cIAP2) and IL-8 promoters and associated with SMRT and HDAC3. Upon activation

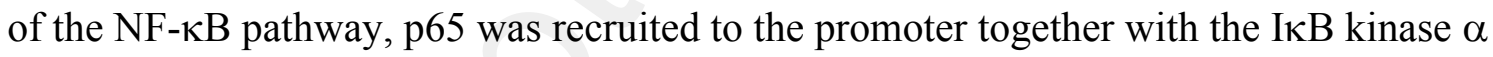
(IKK $\alpha$ ). The phosphorylation of p65 and SMRT by IKK $\alpha$ promoted the release of HDAC3 from the promoter, allowing the acetylation of $\mathrm{H} 3 \mathrm{~K} 14$ and the initiation of transcription (Hoberg et al., 2004; 2006). A similar de-repression step has been described for the activation of AP-1-dependent transcription (Weiss et al., 2003; Ogawa et al., 2004). In resting condition, c-Jun was present together with the nuclear receptor corepressor (NCoR) and HDAC3 at the promoter of AP-1 target genes. Upon induction e.g. by stress or growth factors, c-Jun was phosphorylated by JNK, c-Fos was recruited to the 
promoter, and NCoR and HDAC3 were released from the promoter (Weiss et al., 2003; Ogawa et al., 2004). Similarly, the co-repressors Sin3a, NCoR, HDAC-1 and -3 were present at the promoter of the matrix metalloproteinase (MMP)-9, an AP-1 and NF- $\mathrm{BB}$ target gene, and these co-repressors were released upon activation (Ma et al., 2004).

Since the initial step in the transcriptional activation by both AP-1 and NF- $\kappa$ B involves de-repression, an attractive option to explain negative crosstalk would be an interference by GR with de-repression, for instance by preventing the release of co-repressors from the promoter. Such a mechanism would be compatible with the observed decrease in histone acetylation at the promoter upon GC treatment (Ito et al., 2000; Ito et al., 2001; Nie et al., 2005). What makes this hypothesis particularly attractive is that two other nuclear receptors, PPAR $\gamma$ and the liver $\mathrm{X}$ receptor $\beta \mathrm{LXR} \beta$, were recently reported to repress NF- $\mathrm{BB}$-dependent transcription by preventing the release of co-repressor complexes from the promoter upon induction (Pascual et al., 2005; Ghisletti et al., 2007).

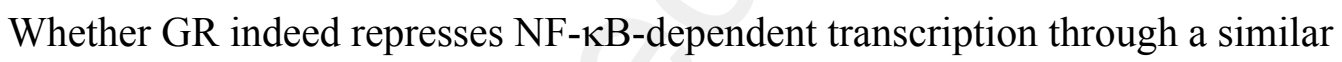
mechanism of inhibited de-repression remains to be determined. However, some experimental evidence suggests that it might not be the case. Blocking the release of corepressor complexes prevented the recruitment of RNA polymerase II (Pol II) to the promoter (Hoberg et al., 2004). Yet, pre-initiation of transcription is apparently not affected by GR, since Pol II was still recruited to the promoter of NF- $\kappa$ B target genes in repressing conditions (Nissen and Yamamoto, 2000; Luecke and Yamamoto, 2005). If these results can be confirmed, they would indicate that GR represses NF- $\kappa$ B at an initiation or even post-initiation step. The mechanism may be different in the repression of other TFs. The trans-repression by GR of NGFI-B/NuR77 apparently occurs at a pre- 
initiation step, since it was associated with a decrease in Pol II recruitment at the promoter (Bilodeau et al., 2006).

\section{Inhibition of Pol II CTD phosphorylation}

Serine phosphorylation of the Pol II carboxy-terminal domain (CTD) is an important regulatory mechanism in transcription initiation and elongation (reviewed in Sims et al., 2004). GR was reported to inhibit serine-2 phosphorylation of the Pol II CTD at the NFКB-dependent IL-8 promoter (Nissen and Yamamoto, 2000). This inhibition was correlated with a lack of recruitment of the Ser2 CTD kinase P-TEFb (positive transcription elongation factor b) to the promoter (Luecke and Yamamoto, 2005). Thus, the inhibition of Ser2 CTD phosphorylation could be a mechanism through which GR represses NF- $\kappa$ B function. However, Ser2 phosphorylation of Pol II CTD is observed in the elongation phase of transcription (reviewed in Sims et al., 2004). It therefore remains to be determined whether the inhibition of this phosphorylation by GR is a cause or a consequence of the repression. In addition, the proposed lack of Ser2 CTD kinase recruitment might be restricted to GR-mediated repression of NF- $\kappa \mathrm{B}$ : the repression of NGFI-B/NuR77 by GR was associated with an apparent decrease in Ser2 phosphorylation of Pol II CTD, which was however strictly correlated with the above mentioned decrease in total Pol II recruitment (Bilodeau et al., 2006).

\section{Interference with histone tail modifications}

The hypothesis that GR represses AP-1- and NF- $\mathrm{KB}$-dependent transcription by interfering with the acetylation of histone tails, has been discussed above. Transcriptional induction also involves other modifications of histone tail residues. The phosphorylation 
of Ser10 of H3 is associated with activation (reviewed in Prigent and Dimitrov, 2003), and this phosphorylation is increased at active promoters of AP-1 and NF- $\kappa \mathrm{B}$ target genes (Martens et al., 2003; Chan et al., 2005; Karrasch et al., 2006). A recent report described a decrease in H3 Ser10 phosphorylation in bulk histone preparations upon GC treatment (Hasegawa et al., 2005). The possible contribution of this inhibition to the repression of AP-1 and NF- $\mathrm{B}$, as well as its mechanism, has to be further investigated.

Another histone modification crucial in the regulation of transcription is methylation. For instance, methylation of H3 Lys9 and 27 is associated with repression, whereas the progressive mono-, di- and trimethylation at H3 Lys4 by the methyltransferase Set9 is required for activation (reviewed in Bannister and Kouzarides, 2005). Another activating signal is provided by methylation of $\mathrm{H} 3 \mathrm{Arg} 2$ and 17 by arginine methyltransferases like the co-activator-associated arginine methyltransferase (CARM)1 (reviewed in Bannister and Kouzarides, 2005). An increase in activating Lys and Arg methylations, associated with the recruitment of the corresponding methyltransferases, and a decrease in repressing Lys methylations have been reported upon activation of AP-1 and NF- $\kappa \mathrm{B}$ regulated promoters (Martens et al., 2003; Ma et al., 2004; Chan et al., 2005; Covic et al., 2005; Miao et al., 2006). However, demethylases responsible for this latter step are not yet known. The putative interference of GR with these de-repression and activation processes has not been addressed. One could imagine that GR inhibits the activating methylation by blocking the recruitment of methyltransferases, or actively promote the demethylation by mediating the recruitment of demethylases. Alternatively, GR might interfere with the activating demethylation or promote repressing methylations. 


\section{In vivo relevance}

GR interferes, positively or negatively, with the transcriptional activity of numerous TFs, and, conversely, these TFs interfere with the transcriptional activity of GR. Probably there is no unifying molecular mechanism for these crosstalks, although several common features have been elaborated and discussed in this review. Most of our knowledge concerning the crosstalk between GR and other TFs comes form in vitro studies. The in vivo relevance of these multiple mechanisms of GR action is yet unknown. Are these crosstalks significant in the physiology of GC and GR? Do they contribute to the therapeutic benefit and/or to the adverse side effects of GCs in e.g. inflammation?

The positive crosstalk between GR and STAT5 was very recently shown to be relevant for the postnatal growth of the mouse (Engblom et al., 2007). Using genetic ablation of GR and STAT5 in mouse liver, the authors showed that a subset of STAT5 target genes was critically dependent on the interaction between STAT5 and GR for expression in mouse liver. Furthermore, the GR-STAT5 positive crosstalk in hepatocytes was critical for the normal growth of mice. However, the reverse crosstalk, i.e. the repression of GRdependent transcription by STAT5 was not observed, suggesting that this negative crosstalk is not relevant in vivo, at least in basal non-challenged conditions (Engblom et al., 2007).

The so-called "dissociated compounds" or SEGRAs promote GR-mediated transrepression of AP-1 and NF- $\mathrm{BB}$, but have a reduced ability to trans-activate GR-target genes. The efficacy of these compounds in animal models of inflammation (reviewed in Miner, 2002; Schäcke et al., 2006) suggested that GR-mediated repression of AP-1 and 
$\mathrm{NF}-\kappa \mathrm{B}$ accounts for some of the beneficial anti-inflammatory effects of GCs. However, the ability of these compounds to mediate the crosstalk between GR and the other TFs remains to be addressed. Similarly, the dimerization defective GR mutant $\mathrm{GR}_{\mathrm{A} 458 \mathrm{~T}}$, the

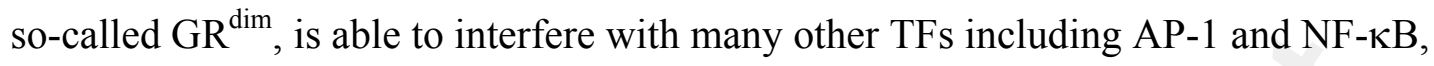
while showing severely impaired trans-activation (see above). The characterization of transgenic knock-in mice carrying the $\mathrm{GR}^{\mathrm{dim}}$ mutation partially documented the relative contribution of trans-activation and negative crosstalk functions in both the physiology of GR (Bauer et al., 1999; Karst et al., 2000; Reichardt et al., 1998; Oitzl et al., 2001) and the therapeutic effects of GCs (Reichardt et al., 2001; Tuckermann et al., 1999; 2007) in vivo. However, the interpretation of these results should be carefully re-evaluated, in view of the recent observation that some direct GR target genes are still induced by dimerization defective GR mutants, including GR ${ }^{\operatorname{dim}}$ (Adams et al., 2003; Rogatsky et al., 2003). Moreover, a recent report showed an impaired GC-mediated repression of some inflammatory cytokines and chemokines in macrophages derived from $\mathrm{GR}^{\mathrm{dim}}$ mice (Tuckermann et al., 2007). This surprising result suggests that GR-mediated transrepression of NF- $\kappa \mathrm{B}$ does not occur in macrophages, at least for some of the evaluated NF- $\kappa \mathrm{B}$ target genes. This also raises the question of the cell-type specificity of GR action. Early reports on the crosstalk function of nuclear receptors seemed to identify differences between endometrial epithelium and other cell lines (Shemshedini et al., 1991).

\section{Concluding remarks}


Multiple mechanisms of GR action have been described, which could all contribute to the therapeutic effects of GCs by for instance decreasing the expression of pro-inflammatory cytokines. Do these different mechanisms coexist? Is there a prevalent mechanism in a given cell type, in a given physiologic or pathologic situation? Moreover, most of these different mode of actions of GR have been described using a single dose of GC, usually applied before or together with the pro-inflammatory stimulus, both in tissue culture systems or in vivo in the mouse. What about the contribution of the different modes of GR action in real life situations, when GCs are used in a chronic manner for the treatment of an already established inflammation? From our compilation of data it is obvious that a more sophisticated organismic analysis of the crosstalk is lacking.

From the molecular point of view, one of the most intriguing questions concerning the negative crosstalk is yet unresolved. How does the structure of multiprotein complexes and the conformational changes produced by one or the other protein-protein interaction turn transcriptional activators into repressors? Although our knowledge of GC actions has enormously increased over the past decades, a significant effort is still needed to fill the gaps. 


\section{Acknowledgements}

The authors are grateful to Andrew Cato and to Carsten Weiss for stimulating discussion and helpful suggestions. Recent work by the authors was supported by the German

Science Foundation (DFG grant no. HE 551/13-1) and by the European Commission (HPRN-CT-2002-00256). 


\section{References:}

Adams, M., Meijer, O.C., Wang, J., Bhargava, A., Pearce, D. (2003). Homodimerization of the glucocorticoid receptor is not essential for response element binding: activation of the phenylethanolamine $\mathrm{N}$-methyltransferase gene by dimerizationdefective mutants. Mol. Endocrinol. 17, 2583-2592.

Akerblom, I.E., Slater, E.P., Beato, M., Baxter, J.D., Mellon, P.L. (1988). Negative regulation by glucocorticoids through interference with a cAMP responsive enhancer. Science 241, 350-353.

Arce, L., Yokoyama, N.N., Waterman, M.L. (2006). Diversity of LEF/TCF action in development disease. Oncogene 25, 7492-7504.

Arias, J., Alberts, A.S., Brindle, P., Claret, F.X., Smeal, T., Karin, M., Feramisco, J., Montminy, M. (1994). Activation of cAMP and mitogen responsive genes relies on a common nuclear factor. Nature 370, 226-229.

Ashburner, B.P., Westerheide, S.D., Baldwin, A.S., Jr. (2001). The p65 (RelA) Subunit of NF- $\kappa \mathrm{B}$ interacts with the histone deacetylase (HDAC) corepressors HDAC1 and HDAC2 to negatively regulate gene expression. Mol. Cell. Biol. 21, 7065-7077.

Bach, I. (2000). The LIM domain: regulation by association. Mech. Dev. 91, 5-17.

Bannister, A.J., Kouzarides, T. (2005). Reversing histone methylation. Nature 436, 1103 1106.

Bauer, A., Tronche, F., Wessely, O., Kellendonk, C., Reichardt, H.M., Steinlein, P., Schutz, G., Beug, H. (1999). The glucocorticoid receptor is required for stress erythropoiesis. Genes Dev. 13, 2996-3002. 
Bilodeau, S., Vallette-Kasic, S., Gauthier, Y., Figarella-Branger, D., Brue, T., Berthelet, F., Lacroix, A., Batista, D., Stratakis, C., Hanson, J., Meij , B., Drouin, J. (2006). Role of Brg1 and HDAC2 in GR trans-repression of the pituitary POMC gene and misexpression in Cushing disease. Genes Dev. 20, 2871-2886.

Biola, A., Andreau, K., David, M., Sturm, M., Haake, M., Bertoglio, J., Pallardy, M. (2000). The glucocorticoid receptor and STAT6 physically and functionally interact in T-lymphocytes. FEBS Lett. 487, 229-233.

Biola, A., Lefebvre, P., Perrin-Wolff, M., Sturm, M., Bertoglio, J., Pallardy, M. (2001). Interleukin-2 inhibits glucocorticoid receptor transcriptional activity through a mechanism involving STAT5 (signal transducer and activator of transcription 5) but not AP-1. Mol. Endocrinol. 15, 1062-1076.

Bledsoe, R.K., Montana, V.G., Stanley, T.B., Delves, C.J., Apolito, C.J., McKee, D.D., Consler, T.G., Parks, D.J., Stewart, E.L., Willson, T.M., Millard H. Lambert, M.H., Moore, J.T., Pearce, K.H., Xu, E.H. (2002). Crystal structure of the glucocorticoid receptor ligand binding domain reveals a novel mode of receptor dimerization and coactivator recognition. Cell 110, 93-105.

Bruggemeier, U., Kalff, M., Franke, S., Scheidereit, C., Beato, M. (1991). Ubiquitous transcription factor OTF-1 mediates induction of the MMTV promoter through synergistic interaction with hormone receptors. Cell 64, 565-572.

Bruna, A., Nicolas, M., Munoz, A., Kyriakis, J.M., Caelles, C. (2003). Glucocorticoid receptor-JNK interaction mediates inhibition of the JNK pathway by glucocorticoids. EMBO J. 22, 6035-6044. 
Burkhart, B.A., Hebbar, P.B., Trotter, K.W., Archer, T.K. (2005). Chromatin-dependent E1A activity modulates NF-kappaB RelA-mediated repression of glucocorticoid receptor-dependent transcription. J. Biol. Chem. 280, 6349-6358.

Caelles, C., Gonzalez-Sancho, J.M., Munoz, A. (1997). Nuclear hormone receptor antagonism with AP-1 by inhibition of the JNK pathway. Genes Dev. 11, 33513364.

Caldenhoven, E., Liden, J., Wissink, S., Van de Stolpe, A., Raaijmakers, J., Koenderman, L., Okret, S., Gustafsson, J.A., Van der Saag, P.T. (1995). Negative cross-talk between RelA and the glucocorticoid receptor: a possible mechanism for the antiinflammatory action of glucocorticoids. Mol. Endocrinol. 9, 401-412.

Chan, C., Li, L., McCall, C.E., Yoza, B.K. (2005). Endotoxin tolerance disrupts chromatin remodeling and NF- $\mathrm{B}$ transactivation at the IL-1 $\beta$ promoter. J. Immunol. 175, 461-468.

Charmandari, E., Kino, T., Souvatzoglou, E., Vottero, A., Bhattacharyya, N., Chrousos, G.P. (2004). Natural glucocorticoid receptor mutants causing generalized glucocorticoid resistance: molecular genotype, genetic transmission, and clinical phenotype. J. Clin. Endocr. Metab. 89, 1939-1949.

Chatterjee, V.K., Madison, L.D., Mayo, S., Jameson, J.L. (1991). Repression of the human glycoprotein hormone alpha-subunit gene by glucocorticoids: evidence for receptor interactions with limiting transcriptional activators. Mol. Endocrinol. 5, $100-110$.

Coghlan, M.J., Jacobson, P.B., Lane, B., Nakane, M., Lin, C.W., Elmore, S.W., Kym, P.R., Luly, J.R., Carter, G.W., Turner, R., Tyree, C.M., Hu, J., Elgort, M., Rosen, 
J., Miner, J.N. (2003). A novel antiinflammatory maintains glucocorticoid efficacy with reduced side effects. Mol. Endocrinol. 17, 860-869.

Covic, M., Hassa, P.O., Saccani, S., Buerki, C., Meier, N.I., Lombardi, C., Imhof, R., Bedford, M.T., Natoli, G., Hottiger, M.O. (2005). Arginine methyltransferase CARM1 is a promoter-specific regulator of NF-kappaB-dependent gene expression. EMBO J. 24, 85-96.

Dahlman-Wright, K., Wright, A., Gustafsson, J.A., Carlstedt-Duke, J. (1991). Interaction of the glucocorticoid receptor DNA-binding domain with DNA as a dimer is mediated by a short segment of five amino acids. J. Biol. Chem. 266, 3107-3112.

Davis, R.J. (1995). Transcriptional regulation by MAP kinases. Mol. Reprod. Dev. 42, 459-467.

De Bosscher, K., Schmitz, M.L., Vanden Berghe, W., Plaisance, S., Fiers, W., Haegeman, G. (1997). Glucocorticoid-mediated repression of nuclear factorkappaB-dependent transcription involves direct interference with transactivation. Proc. Natl. Acad. Sci. USA 94, 13504-13509.

De Bosscher, K., Vanden Berghe, W., Haegeman, G. (2001). Glucocorticoid repression of AP-1 is not mediated by competition for nuclear coactivators. Mol. Endocrinol. $15,219-227$.

De Bosscher, K., Vanden Berghe, W., Vermeulen, L., Plaisance, S., Boone, E., Haegeman, G. (2000). Glucocorticoids repress NF-kappaB-driven genes by disturbing the interaction of p65 with the basal transcription machinery, irrespective of coactivator levels in the cell. Proc. Natl. Acad. Sci. USA 97, 3919-3924. 
de Lange, P., Koper, J.W., Huizenga, N.A., Brinkmann, A.O., de Jong, F.H., Karl, M., Chrousos, G.P., Lamberts, S.W. (1997). Differential hormone-dependent transcriptional activation and -repression by naturally occurring human glucocorticoid receptor variants. Mol. Endocrinol. 11, 1156-1164.

de Martino, M.U., Bhattachryya, N., Alesci, S., Ichijo, T., Chrousos, G.P., Kino, T. (2004). The glucocorticoid receptor and the orphan nuclear receptor chicken ovalbumin upstream promoter-transcription factor II interact with and mutually affect each other's transcriptional activities: implications for intermediary metabolism. Mol. Endocrinol. 18, 820-833.

Diamond, M.I., Miner, J.N., Yoshinaga, S.K., Yamamoto, K.R. (1990). Transcription factor interactions: selectors of positive or negative regulation from a single DNA element. Science 249, 1266-1272.

Doppler, W., Windegger, M., Soratroi, C., Tomasi, J., Lechner, J., Rusconi, S., Cato, A.C., Almlof, T., Liden, J., Okret, S., Gustafsson, J.A., Richard-Foy, H., Starr, D.B., Klocker, H., Edwards, D., Geymayer, S. (2001). Expression level-dependent contribution of glucocorticoid receptor domains for functional interaction with STAT5. Mol. Cell. Biol. 21, 3266-3279.

Engblom, D., Kornfeld, J.-W., Schwake, L., Tronche, F., Reimann, A., Beug, H., Hennighausen, L., Moriggl, R., Schütz, G. (2007) Direct glucocorticoid receptorStat5 interaction in hepatocytes controls body size and maturation-related gene expression. Genes Dev. 21, 1157-1162. 
Espinas, M.L., Roux, J., Ghysdael, J., Pictet, R., Grange, T. (1994). Participation of Ets transcription factors in the glucocorticoid response of the rat tyrosine aminotransferase gene. Mol. Cell. Biol. 14, 4116-4125.

Garside, H., Stevens, A., Farrow, S., Normand, C., Houle, B., Berry, A., Maschera, B., Ray, D. (2004). Glucocorticoid ligands specify different interactions with NFkappaB by allosteric effects on the glucocorticoid receptor DNA binding domain. J. Biol. Chem. 279, 50050-50059.

Gauthier, J.M., Bourachot, B., Doucas, V., Yaniv, M., Moreau-Gachelin, F. (1993). Functional interference between the Spi-1/PU.1 oncoprotein and steroid hormone or vitamin receptors. EMBO J. 12, 5089-5096.

Ghisletti, S., Huang, W., Ogawa, S., Pascual, G., Lin, M.E., Willson, T.M., Rosenfeld, M.G., Glass, C.K. (2007). Parallel SUMOylation-dependent pathways mediate gene- and signal-specific transrepression by LXRs and PPARgamma. Mol. Cell 25, 57-70.

Ghogomu, S.M., van Venrooy, S., Ritthaler, M., Wedlich, D., Gradl, D. (2006). HIC-5 is a novel repressor of lymphoid enhancer factor/T-cell factor-driven transcription. J. Biol. Chem. 281, 1755-1764.

Gonzalez, M.V., Jimenez, B., Berciano, M.T., Gonzalez-Sancho, J.M., Caelles, C., Lafarga, M., Munoz, A. (2000). Glucocorticoids antagonize AP-1 by inhibiting the Activation/phosphorylation of JNK without affecting its subcellular distribution. J. Cell. Biol. 150, 1199-1208.

Griekspoor, A., Zwart, W., Neefjes, J., Michalides, R. (2007). Visualizing the action of steroid hormone receptors in living cells. Nucelar Receptor Signaling 5, e003. 
Gronemeyer, H., Gustafsson, J.A., Laudet, V. (2004). Principles for modulation of the nuclear receptor superfamily. Nat. Rev. Drug Discov. 3, 950-964.

Hasegawa, Y., Tomita, K., Watanabe, M., Yamasaki, A., Sano, H., Hitsuda, Y., Shimizu, E. (2005). Dexamethasone inhibits phosphorylation of histone H3 at serine 10 . Biochem. Biophys. Res. Commun. 336, 1049-1055.

He, Y., Simons, S.S., Jr. (2007). STAMP, a novel predicted factor assisting TIF2 actions in glucocorticoid receptor-mediated induction and repression. Mol. Cell. Biol. 27, 1467-1485.

Heck, S., Bender, K., Kullmann, M., Göttlicher, M., Herrlich, P., Cato, A.C. (1997). I kappaB alpha-independent downregulation of NF-kappaB activity by glucocorticoid receptor. EMBO J. 16, 4698-4707.

Heck, S., Kullmann, M., Gast, A., Ponta, H., Rahmsdorf, H.J., Herrlich, P., Cato, A.C. (1994). A distinct modulating domain in glucocorticoid receptor monomers in the repression of activity of the transcription factor AP-1. EMBO J. 13, 4087-4095.

Hirasawa, N., Sato, Y., Fujita, Y., Mue, S., Ohuchi, K. (1998). Inhibition by dexamethasone of antigen-induced c-Jun N-terminal kinase activation in rat basophilic leukemia cells. J. Immunol. 161, 4939-4943.

Hoberg, J.E., Popko, A.E., Ramsey, C.S., Mayo, M.W. (2006). IкB kinase $\alpha$-mediated derepression of SMRT potentiates acetylation of RelA/p65 by p300. Mol. Cell. Biol. 26, 457-471.

Hoberg, J.E., Yeung, F., Mayo, M.W. (2004). SMRT Derepression by the IкB Kinase $\alpha$ : A Prerequisite to NF-кB Transcription and Survival. Mol. Cell 16, 245-255. 
Huang, S.M., Cheng, Y.S. (2004). Analysis of two CBP (cAMP-response-elementbinding protein-binding protein) interacting sites in GRIP1 (glucocorticoidreceptor-interacting protein), and their importance for the function of GRIP1. Biochem. J. 382, 111-119.

Hulley, P.A., Gordon, F., Hough, F.S. (1998). Inhibition of mitogen-activated protein kinase activity and proliferation of an early osteoblast cell line (MBA 15.4) by dexamethasone: role of protein phosphatases. Endocrinol. 139, 2423-2431.

Hurley, D.M., Accili, D., Stratakis, C.A., Karl, M., Vamvakopoulos, N., Rorer, E., Constantine, K., Taylor, S.I., Chrousos, G.P. (1991). Point mutation causing a single amino acid substitution in the hormone binding domain of the glucocorticoid receptor in familial glucocorticoid resistance. J. Clin. Invest. 87, 680-686.

Ichijo, T., Voutetakis, A., Cotrim, A.P., Bhattachryya, N., Fujii, M., Chrousos, G.P., Kino, T. (2005). The Smad6-histone deacetylase 3 complex silences the transcriptional activity of the glucocorticoid receptor: potential clinical implications. J. Biol. Chem. 280, 42067-42077.

Imai, E., Miner, J.N., Mitchell, J.A., Yamamoto, K.R., Granner, D.K. (1993).

Glucocorticoid receptor-cAMP response element-binding protein interaction and the response of the phosphoenolpyruvate carboxykinase gene to glucocorticoids. J. Biol. Chem. 268, 5353-5356.

Imasato, A., Desbois-Mouthon, C., Han, J., Kai, H., Cato, A.C., Akira, S., Li, J.D. (2002). Inhibition of p38 MAPK by glucocorticoids via induction of MAPK phosphatase-1 enhances nontypeable Haemophilus influenzae-induced expression of toll-like receptor 2. J. Biol. Chem. 277, 47444-47450. 
Ito, K., Barnes, P.J., Adcock, I.M. (2000). Glucocorticoid receptor recruitment of histone deacetylase 2 inhibits interleukin-1beta-induced histone $\mathrm{H} 4$ acetylation on lysines 8 and 12. Mol. Cell. Biol. 20, 6891-6903.

Ito, K., Jazrawi, E., Cosio, B., Barnes, P.J., Adcock, I.M. (2001). p65-activated histone acetyltransferase activity is repressed by glucocorticoids: mifepristone fails to recruit HDAC2 to the p65-HAT complex. J. Biol. Chem. 276, 30208-30215.

Ito, K., Yamamura, S., Essilfie-Quaye, S., Cosio, B., Ito, M., Barnes, P.J., Adcock, I.M. (2006). Histone deacetylase 2-mediated deacetylation of the glucocorticoid receptor enables NF-kappaB suppression. J. Exp. Med. 203, 7-13.

Jee, Y.K., Gilmour, J., Kelly, A., Bowen, H., Richards, D., Soh, C., Smith, P., Hawrylowicz, C., Cousins, D., Lee, T., Lavender, P. (2005). Repression of interleukin-5 transcription by the glucocorticoid receptor targets GATA3 signaling and involves histone deacetylase recruitment. J. Biol. Chem. 280, 23243-23250.

Jenkins, B.D., Pullen, C.B., Darimont, B.D. (2001). Novel glucocorticoid receptor coactivator effector mechanisms. Trends Endocrinol. Metab. 12, 122-126.

Jonat, C., Rahmsdorf, H.J., Park, K.K., Cato, A.C., Gebel, S., Ponta, H., Herrlich, P. (1990). Antitumor promotion and antiinflammation: down-modulation of AP-1 (Fos/Jun) activity by glucocorticoid hormone. Cell 62, 1189-1204.

Kadrmas, J.L., Beckerle, M.C. (2004). The LIM domain: from the cytoskeleton to the nucleus. Nat. Rev. Mol. Cell. Biol. 5, 920-931.

Kamei, Y., Xu, L., Heinzel, T., Torchia, J., Kurokawa, R., Gloss, B., Lin, S.C., Heyman, R.A., Rose, D.W., Glass, C.K., Rosenfeld, M.G. (1996). A CBP integrator complex 
mediates transcriptional activation and AP-1 inhibition by nuclear receptors. Cell $85,403-414$.

Karin, M., Haslinger, A., Holtgreve, H., Richards, R.I., Krauter, P., Westphal, H.M., Beato, M. (1984). Characterization of DNA sequences through which cadmium and glucocorticoid hormones induce human metallothionein-IIA gene. Nature 308, 513519.

Karrasch, T., Steinbrecher, K.A., Allard, B., Baldwin, A.S., Jobin, C. (2006). Woundinduced p38MAPK-dependent histone H3 phosphorylation correlates with increased COX-2 expression in enterocytes. J. Cell. Physiol. 207, 809-815.

Karst, H., Karten, Y.J., Reichardt, H.M., de Kloet, E.R., Schutz, G., Joels, M. (2000). Corticosteroid actions in hippocampus require DNA binding of glucocorticoid receptor homodimers. Nature Neurosci. 3, 977-978.

Kassel, O., Sancono, A., Kratzschmar, J., Kreft, B., Stassen, M., Cato, A.C. (2001). Glucocorticoids inhibit MAP kinase via increased expression and decreased degradation of MKP-1. EMBO J. 20, 7108-7116.

Kassel, O., Schneider, S., Heilbock, C., Litfin, M., Göttlicher, M., Herrlich, P. (2004). A nuclear isoform of the focal adhesion LIM-domain protein Trip6 integrates

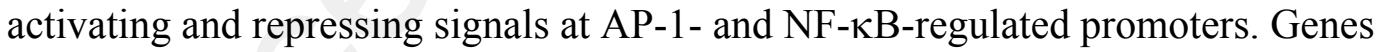
Dev. 18, 2518-2528.

Kellendonk, C., Tronche, F., Reichardt, H.M., Bauer, A., Greiner, E., Schmid, W., Schutz, G. (2002). Analysis of glucocorticoid receptor function in the mouse by gene targeting. Ernst Schering Res. Found. Workshop, 305-318. 
Kerppola, T.K., Luk, D., Curran, T. (1993). Fos is a preferential target of glucocorticoid receptor inhibition of AP-1 activity in vitro. Mol. Cell. Biol. 13, 3782-3791.

Ki, S.H., Cho, I.J., Choi, D.W., Kim, S.G. (2005). Glucocorticoid receptor (GR)associated SMRT binding to C/EBP $\beta$ TAD and Nrf2 Neh4/5: role of SMRT recruited to GR in GSTA2 gene repression. Mol. Cell. Biol. 25, 4150-4165.

König, H., Ponta, H., Rahmsdorf, H.J., Herrlich, P. (1992). Interference between pathway-specific transcription factors: glucocorticoids antagonize phorbol esterinduced AP-1 activity without altering AP-1 site occupation in vivo. EMBO J. 11, 2241-2246.

Kucera, T., Waltner-Law, M., Scott, D.K., Prasad, R., Granner, D.K. (2002). A point mutation of the AF2 transactivation domain of the glucocorticoid receptor disrupts its interaction with steroid receptor coactivator 1. J. Biol. Chem. 277, 26098-26102.

Kunz, S., Sandoval, R., Carlsson, P., Carlstedt-Duke, J., Bloom, J.W., Miesfeld, R.L. (2003). Identification of a novel glucocorticoid receptor mutation in budesonideresistant human bronchial epithelial cells. Mol. Endocrinol. 17, 2566-2582.

Kuo, M.H., Allis, C.D. (1998). Roles of histone acetyltransferases and deacetylases in gene regulation. Bioessay. 20, 615-626.

Kutoh, E., Stromstedt, P.E., Poellinger, L. (1992). Functional interference between the ubiquitous and constitutive octamer transcription factor $1(\mathrm{OTF}-1)$ and the glucocorticoid receptor by direct protein-protein interaction involving the homeo subdomain of OTF-1. Mol. Cell. Biol. 12, 4960-4969. 
Kwok, R.P., Lundblad, J.R., Chrivia, J.C., Richards, J.P., Bachinger, H.P., Brennan, R.G., Roberts, S.G., Green, M.R., Goodman, R.H. (1994). Nuclear protein CBP is a coactivator for the transcription factor CREB. Nature 370, 223-226.

Lasa, M., Abraham, S.M., Boucheron, C., Saklatvala, J., Clark, A.R. (2002).

Dexamethasone causes sustained expression of mitogen-activated protein kinase (MAPK) phosphatase 1 and phosphatase-mediated inhibition of MAPK p38. Mol. Cell. Biol. 22, 7802-7811.

Lasa, M., Brook, M., Saklatvala, J., Clark, A.R. (2001). Dexamethasone destabilizes cyclooxygenase 2 mRNA by inhibiting mitogen-activated protein kinase p38. Mol. Cell. Biol. 21, 771-780.

Lechner, J., Welte, T., Tomasi, J.K., Bruno, P., Cairns, C., Gustafsson, J., Doppler, W. (1997). Promoter-dependent synergy between glucocorticoid receptor and Stat5 in the activation of beta-casein gene transcription. J. Biol. Chem. 272, 20954-20960.

Lee, S.K., Kim, H.J., Na, S.Y., Kim, T.S., Choi, H.S., Im, S.Y., Lee, J.W. (1998). Steroid receptor coactivator-1 coactivates activating protein-1-mediated transactivations through interaction with the c-Jun and c-Fos subunits. J. Biol. Chem. 273, 1665116654.

Lerner, L., Henriksen, M.A., Zhang, X., Darnell, J.E., Jr. (2003). STAT3-dependent enhanceosome assembly and disassembly: synergy with GR for full transcriptional increase of the alpha 2-macroglobulin gene. Genes Dev. 17, 2564-2577.

Liberman, A.C., Refojo, D., Druker, J., Toscano, M., Rein, T., Holsboer, F., Arzt, E. (2007). The activated glucocorticoid receptor inhibits the transcription factor T-bet by direct protein-protein interaction. FASEB J. 21, 1177-1188. 
Liden, J., Delaunay, F., Rafter, I., Gustafsson, J., Okret, S. (1997). A new function for the C-terminal zinc finger of the glucocorticoid receptor. Repression of RelA transactivation. J. Biol. Chem. 272, 21467-21472.

Liu, J.L., Papachristou, D.N., Patel, Y.C. (1994). Glucocorticoids activate somatostatin gene transcription through co-operative interaction with the cyclic AMP signalling pathway. Biochem. J. 301, 863-869.

Liu, P.-Y., Hsieh, T.-Y., Chou, W.-Y., Huang, S.-M. (2006). Modulation of glucocorticoid receptor-interacting protein 1 (GRIP1) transactivation and coactivation activities through its $\mathrm{C}$-terminal repression and self-association domains. FEBS J. 273, 2172-2183.

Lucibello, F.C., Slater, E.P., Jooss, K.U., Beato, M., Muller, R. (1990). Mutual transrepression of Fos and the glucocorticoid receptor: involvement of a functional domain in Fos which is absent in FosB. EMBO J. 9, 2827-2834.

Luecke, H.F., Yamamoto, K.R. (2005). The glucocorticoid receptor blocks P-TEFb recruitment by NFkappaB to effect promoter-specific transcriptional repression. Genes Dev. 19, 1116-1127.

Ma, Z., Shah, R.C., Chang, M.J., Benveniste, E.N. (2004). Coordination of cell signaling, chromatin remodeling, histone modifications, and regulator recruitment in human matrix metalloproteinase 9 gene transcription. Mol. Cell. Biol. 24, 5496-5509.

Martens, C., Bilodeau, S., Maira, M., Gauthier, Y., Drouin, J. (2005). Protein-protein interactions and transcriptional antagonism between the subfamily of NGFIB/Nur77 orphan nuclear receptors and glucocorticoid receptor. Mol. Endocrinol. $19,885-897$. 
Martens, J.A., Winston, F. (2003). Recent advances in understanding chromatin remodeling by Swi/Snf complexes. Cur. Opin. Genet. Dev. 13, 136-142.

Martens, J.H., Verlaan, M., Kalkhoven, E., Zantema, A. (2003). Cascade of distinct histone modifications during collagenase gene activation. Mol. Cell. Biol. 23, 18081816.

McKay, L.I., Cidlowski, J.A. (1998). Cross-talk between nuclear factor-kappa B and the steroid hormone receptors: mechanisms of mutual antagonism. Mol. Endocrinol. $12,45-56$.

McKay, L.I., Cidlowski, J.A. (2000). CBP (CREB binding protein) integrates NF-kappaB (nuclear factor-kappaB) and glucocorticoid receptor physical interactions and antagonism. Mol. Endocrinol. 14, 1222-1234.

Miao, F., Li, S., Chavez, V., Lanting, L., Natarajan, R. (2006). Coactivator-associated arginine methyltransferase-1 enhances Nuclear Factor- $\kappa$ B-mediated gene transcription through methylation of histone H3 at arginine 17. Mol. Endocrinol. $20,1562-1573$.

Miksicek, R., Borgmeyer, U., Nowock, J. (1987). Interaction of the TGGCA-binding protein with upstream sequences is required for efficient transcription of mouse mammary tumor virus. EMBO J. 6, 1355-1360.

Miner, J.N. (2002). Designer glucocorticoids. Biochem. Pharmacol. 64, 355-361.

Mukaida, N., Morita, M., Ishikawa, Y., Rice, N., Okamoto, S., Kasahara, T., Matsushima, K. (1994). Novel mechanism of glucocorticoid-mediated gene repression. Nuclear factor-kappa B is target for glucocorticoid-mediated interleukin 8 gene repression. J. Biol. Chem. 269, 13289-13295. 
Mullick, J., Anandatheerthavarada, H.K., Amuthan, G., Bhagwat, S.V., Biswas, G., Camasamudram, V., Bhat, N.K., Reddy, S.E., Rao, V., Avadhani, N.G. (2001). Physical interaction and functional synergy between glucocorticoid receptor and Ets 2 proteins for transcription activation of the rat cytochrome $\mathrm{P}-450 \mathrm{c} 27$ promoter. J. Biol. Chem. 276, 18007-18017.

Na, S.-Y., Lee, S.-K., Han, S.-J., Choi, H.-S., Im, S.-Y., Lee, J.W. (1998). Steroid Receptor Coactivator-1 interacts with the p50 subunit and coactivates Nuclear Factor kappa B-mediated transactivations. J. Biol. Chem. 273, 10831-10834.

Nie, M., Knox, A.J., Pang, L. (2005). beta2-Adrenoceptor agonists, like glucocorticoids, repress eotaxin gene transcription by selective inhibition of histone $\mathrm{H} 4$ acetylation. J. Immunol. 175, 478-486.

Nissen, R.M., Yamamoto, K.R. (2000). The glucocorticoid receptor inhibits NFkappaB by interfering with serine-2 phosphorylation of the RNA polymerase II carboxyterminal domain. Genes Dev. 14, 2314-2329.

Novak, A., Dedhar, S. (1999). Signaling through beta-catenin and Lef/Tcf. Cell. Mol. Life Sci. 56, 523-537.

Ogawa, S., Lozach, J., Benner, C., Pascual, G., Tangirala, R.K., Westin, S., Hoffmann, A., Subramaniam, S., David, M., Rosenfeld, M.G., Glass, C.K.. (2005). Molecular determinants of crosstalk between nuclear receptors and toll-like receptors. Cell $122,707-721$.

Ogawa, S., Lozach, J., Jepsen, K., Sawka-Verhelle, D., Perissi, V., Sasik, R., Rose, D.W., Johnson, R.S., Rosenfeld, M.G., Glass, C.K. (2004). A nuclear receptor corepressor 
transcriptional checkpoint controlling activator protein 1-dependent gene networks required for macrophage activation. Proc. Natl. Acad. Sci. USA 101, 14461-14466.

Ohnaka, K., Tanabe, M., Kawate, H., Nawata, H., Takayanagi, R. (2005). Glucocorticoid suppresses the canonical Wnt signal in cultured human osteoblasts. Biochem. Biophys. Res. Commun. 329, 177-181.

Ohnaka, K., Taniguchi, H., Kawate, H., Nawata, H., Takayanagi, R. (2004)

Glucocorticoid enhances the expression of dickkopf-1 in human osteoblasts: novel mechanism of glucocorrticoid-induced osteoporosis Biochem. Biophys. Res. Commun. 318, 259-264.

Oitzl, M.S., Reichardt, H.M., Joels, M., de Kloet, E.R. (2001). Point mutation in the mouse glucocorticoid receptor preventing DNA binding impairs spatial memory. Proc. Natl. Acad. Sci. USA 98, 12790-12795.

Onate, S.A., Tsai, S.Y., Tsai, M.J., O'Malley, B.W. (1995). Sequence and characterization of a coactivator for the steroid hormone receptor superfamily. Science 270, 1354-1357.

Pascual, G., Fong, A.L., Ogawa, S., Gamliel, A., Li, A.C., Perissi, V., Rose, D.W., Willson, T.M., Rosenfeld, M.G., Glass, C.K. (2005). A SUMOylation-dependent pathway mediates transrepression of inflammatory response genes by PPARgamma. Nature 437, 759-763.

Perkins, N.D., Felzien, L.K., Betts, J.C., Leung, K., Beach, D.H., Nabel, G.J. (1997). Regulation of NF-kappaB by cyclin-dependent kinases associated with the p300 coactivator. Science 275, 523-527. 
Pfitzner, E., Jahne, R., Wissler, M., Stoecklin, E., Groner, B. (1998). p300/CREB-binding protein enhances the prolactin-mediated transcriptional induction through direct interaction with the transactivation domain of Stat5, but does not participate in the Stat5-mediated suppression of the glucocorticoid response. Mol. Endocrinol. 12, 1582-1593.

Philips, A., Maira, M., Mullick, A., Chamberland, M., Lesage, S., Hugo, P., Drouin, J. (1997). Antagonism between Nur77 and glucocorticoid receptor for control of transcription. Mol. Cell. Biol. 17, 5952-5959.

Prefontaine, G.G., Lemieux, M.E., Giffin, W., Schild-Poulter, C., Pope, L., LaCasse, E., Walker, P., Hache, R.J. (1998). Recruitment of octamer transcription factors to DNA by glucocorticoid receptor. Mol. Cell. Biol. 18, 3416-3430.

Prigent, C., Dimitrov, S. (2003). Phosphorylation of serine 10 in histone H3, what for? J. Cell. Sci. 116, 3677-3685.

Ray, A., LaForge, K.S., Sehgal, P.B. (1991). Repressor to activator switch by mutations in the first $\mathrm{Zn}$ finger of the glucocorticoid receptor: is direct DNA binding necessary? Proc. Natl. Acad. Sci. USA 88, 7086-7090.

Ray, A., Prefontaine, K.E. (1994). Physical association and functional antagonism between the p65 subunit of transcription factor NF-kappa B and the glucocorticoid receptor. Proc. Natl. Acad. Sci. USA 91, 752-756.

Ray, D.W., Suen, C.S., Brass, A., Soden, J., White, A. (1999). Structure/function of the human glucocorticoid receptor: tyrosine 735 is important for transactivation. Mol. Endocrinol. 13, 1855-1863. 
Reichardt, H.M., Kaestner, K.H., Tuckermann, J., Kretz, O., Wessely, O., Bock, R., Gass, P., Schmid, W., Herrlich, P., Angel, P., Schütz, G. (1998). DNA binding of the glucocorticoid receptor is not essential for survival. Cell 93, 531-541.

Reichardt, H.M., Tuckermann, J.P., Göttlicher, M., Vujic, M., Weih, F., Angel, P., Herrlich, P., Schutz, G. (2001). Repression of inflammatory responses in the absence of DNA binding by the glucocorticoid receptor. EMBO J. 20, 7168-7173.

Reily, M.M., Pantoja, C., Hu, X., Chinenov, Y., Rogatsky, I. (2006). The GRIP1:IRF3 interaction as a target for glucocorticoid receptor-mediated immunosuppression. EMBO J. 25, 108-117.

Rider, L.G., Hirasawa, N., Santini, F., Beaven, M.A. (1996). Activation of the mitogenactivated protein kinase cascade is suppressed by low concentrations of dexamethasone in mast cells. J. Immunol. 157, 2374-2380.

Rogatsky, I., Luecke, H.F., Leitman, D.C., Yamamoto, K.R. (2002). Alternate surfaces of transcriptional coregulator GRIP1 function in different glucocorticoid receptor activation and repression contexts. Proc. Natl. Acad. Sci. USA 99, 16701-16706.

Rogatsky, I., Wang, J.C., Derynck, M.K., Nonaka, D.F., Khodabakhsh, D.B., Haqq, C.M., Darimont, B.D., Garabedian, M.J., Yamamoto, K.R. (2003). Target-specific utilization of transcriptional regulatory surfaces by the glucocorticoid receptor. Proc. Natl. Acad. Sci. USA 100, 13845-13850.

Rogatsky, I., Zarember, K.A., Yamamoto, K.R. (2001). Factor recruitment and TIF2/GRIP1 corepressor activity at a collagenase-3 response element that mediates regulation by phorbol esters and hormones. EMBO J. 20, 6071-6083. 
Sakai, D.D., Helms, S., Carlstedt-Duke, J., Gustafsson, J.A., Rottman, F.M., Yamamoto, K.R. (1988). Hormone-mediated repression: a negative glucocorticoid response element from the bovine prolactin gene. Genes Dev. 2, 1144-1154.

Savkur, R.S., Burris, T.P. (2004). The coactivator LXXLL nuclear receptor recognition motif. J. Peptide Research 63, 207-212.

Schaaf, M.J., Cidlowski, J.A. (2002). Molecular mechanisms of glucocorticoid action and resistance. J. Steroid. Biochem. Mol. Biol. 83, 37-48.

Schäcke, H., Rehwinkel, H., Asadullah, K., Cato, A.C. (2006). Insight into the molecular mechanisms of glucocorticoid receptor action promotes identification of novel ligands with an improved therapeutic index. Exp. Dermatol. 15, 565-573.

Scheinman, R.I., Gualberto, A., Jewell, C.M., Cidlowski, J.A., Baldwin, A.S., Jr. (1995). Characterization of mechanisms involved in transrepression of NF-kappa B by activated glucocorticoid receptors. Mol. Cell. Biol. 15, 943-953.

Schena, M., Freedman, L.P., Yamamoto, K.R. (1989). Mutations in the glucocorticoid receptor zinc finger region that distinguish interdigitated DNA binding and transcriptional enhancement activities. Genes Dev. 3, 1590-1601.

Schoneveld, O.J., Gaemers, I.C., Lamers, W.H. (2004). Mechanisms of glucocorticoid signalling. Biochim. Biophys. Acta 1680, 114-128

Schüle, R., Rangarajan, P., Kliewer, S., Ransone, L.J., Bolado, J., Yang, N., Verma, I.M., Evans, R.M. (1990). Functional antagonism between oncoprotein c-Jun and the glucocorticoid receptor. Cell 62, 1217-1226. 
Shemshedini, L., Knauthe, R., Sassone-Corsi, P., Pornon, A., Gronemeyer, H. (1991). Cell-specific inhibitory and stimulatory effects of Fos and Jun on transcription activation by nuclear receptors. EMBO J. 10, 3839-3849.

Sheppard, K.A., Phelps, K.M., Williams, A.J., Thanos, D., Glass, C.K., Rosenfeld, M.G., Gerritsen, M.E., Collins, T. (1998). Nuclear integration of glucocorticoid receptor and nuclear factor-kappaB signaling by CREB-binding protein and steroid receptor coactivator-1. J. Biol. Chem. 273, 29291-29294.

Shi, Y., Gaestel, M. (2002). In the cellular garden of forking paths: how p38 MAPKs signal for downstream assistance. Biol. Chem. 383, 1519-1536.

Simone, C. (2006). SWI/SNF: The crossroads where extracellular signaling pathways meet chromatin. J. Cell. Physiol. 207, 309-314.

Sims, R.J., III, Belotserkovskaya, R., Reinberg, D. (2004). Elongation by RNA polymerase II: the short and long of it. Genes Dev. 18, 2437-2468.

Smith, E., Frenkel, B. (2005). Glucocorticoids inhibit the transcriptional activity of LEF/TCF in differentiating osteoblasts in a glycogen synthase kinase-3betadependent and -independent manner. J. Biol. Chem. 280, 2388-2394.

Song, C.Z., Tian, X., Gelehrter, T.D. (1999). Glucocorticoid receptor inhibits transforming growth factor-beta signaling by directly targeting the transcriptional activation function of Smad3. Proc. Natl. Acad. Sci. USA 96, 11776-11781.

Stauber, C., Altschmied, J., Akerblom, I.E., Marron, J.L., Mellon, P.L. (1992). Mutual cross-interference between glucocorticoid receptor and CREB inhibits transactivation in placental cells. New Biol. 4, 527-540. 
Stevens, A., Garside, H., Berry, A., Waters, C., White, A., Ray, D. (2003). Dissociation of steroid receptor coactivator 1 and nuclear receptor corepressor recruitment to the human glucocorticoid receptor by modification of the ligand-receptor interface: the role of tyrosine 735 . Mol. Endocrinol. 17, 845-859.

Stöcklin, E., Wissler, M., Gouilleux, F., Groner, B. (1996). Functional interactions between Stat5 and the glucocorticoid receptor. Nature 383, 726-728.

Stoecklin, E., Wissler, M., Moriggl, R., Groner, B. (1997). Specific DNA binding of Stat5, but not of glucocorticoid receptor, is required for their functional cooperation in the regulation of gene transcription. Mol. Cell. Biol. 17, 6708-6716.

Strömstedt, P.E., Poellinger, L., Gustafsson, J.A., Carlstedt-Duke, J. (1991). The glucocorticoid receptor binds to a sequence overlapping the TATA box of the human osteocalcin promoter: a potential mechanism for negative regulation. Mol. Cell. Biol. 11, 3379-3383.

Subramaniam, N., Cairns, W., Okret, S. (1998). Glucocorticoids repress transcription from a negative glucocorticoid response element recognized by two homeodomaincontaining proteins, Pbx and Oct-1. J. Biol. Chem. 273, 23567-23574.

Swantek, J.L., Cobb, M.H., Geppert, T.D. (1997). Jun N-terminal kinase/stress-activated protein kinase (JNK/SAPK) is required for lipopolysaccharide stimulation of tumor necrosis factor alpha (TNF-alpha) translation: glucocorticoids inhibit TNF-alpha translation by blocking JNK/SAPK. Mol. Cell. Biol. 17, 6274-6282.

Takeda, T., Kurachi, H., Yamamoto, T., Nishio, Y., Nakatsuji, Y., Morishige, K., Miyake, A., Murata, Y. (1998). Crosstalk between the interleukin-6 (IL-6)-JAK- 
STAT and the glucocorticoid-nuclear receptor pathway: synergistic activation of IL-6 response element by IL-6 and glucocorticoid. J. Endocrinol. 159, 323-330. Touray, M., Ryan, F., Jaggi, R., Martin, F. (1991). Characterisation of functional inhibition of the glucocorticoid receptor by Fos/Jun. Oncogene 6, 1227-1234. Tuckermann, J.P., Kleiman, A., McPherson, K.G., Reichardt, H.M. (2005). Molecular mechanisms of glucocorticoids in the control of inflammation and lymphocyte apoptosis. Crit. Rev. Clin. Lab. Sci. 42, 71-104.

Tuckermann, J.P., Kleiman, A., Moriggl, R., Spanbroek, R., Neumann, A., Illing, A., Clausen, B.E., Stride, B., Förster, I., Habenicht, A.J.R., Reichardt, H.M. Tronche, F., Schmid, W., Schütz, G. (2007). Macrophages and neutrophils are the targets for immune suppression by glucocorticoids in contact allergy J. Clin. Invest. in press. Tuckermann, J.P., Reichardt, H.M., Arribas, R., Richter, K.H., Schutz, G., Angel, P. (1999). The DNA binding-independent function of the glucocorticoid receptor mediates repression of AP-1-dependent genes in skin. J. Cell. Biol. 147, 1365-1370. Umesono, K., Evans, R.M. (1989). Determinants of target gene specificity for steroid/thyroid hormone receptors. Cell 57, 1139-1146.

Vanden Berghe, W., De Bosscher, K., Vermeulen, L., De Wilde, G., Haegeman, G. (2002). Induction and repression of NF-kappa B-driven inflammatory genes. Ernst Schering Res .Found. Workshop, 233-278.

Weiss, C., Schneider, S., Wagner, E.F., Zhang, X., Seto, E., Bohmann, D. (2003). JNK phosphorylation relieves HDAC3-dependent suppression of the transcriptional activity of c-Jun. EMBO J. 22, 3686-3695. 
Wieland, S., Dobbeling, U., Rusconi, S. (1991). Interference and synergism of glucocorticoid receptor and octamer factors. EMBO J. 10, 2513-2521.

Wietek, C., Miggin, S.M., Jefferies, C.A., O'Neill, L.A.J. (2003). Interferon regulatory factor-3-mediated activation of the interferon-sensitive response element by Tolllike receptor (TLR) 4 but not TLR3 requires the p65 subunit of NF-кB. J. Biol. Chem. 278, 50923-50931.

Wu, H.-Y., Hamamori, Y., Xu, J., Chang, S.C., Saluna, T., Chang, M.-F., O'Malley, B.W., Kedes, L. (2005). Nuclear hormone receptor coregulator GRIP1 suppresses, whereas SRC1A and p/CIP coactivate, by domain-specific binding of MyoD. J. Biol. Chem. 280, 3129-3137.

Wu, J., Li, Y., Dietz, J., and Lala, D.S. (2004). Repression of p65 transcriptional activation by the glucocorticoid receptor in the absence of receptor-coactivator interactions. Mol. Endocrinol. 18, 53-62.

Xu, L., Glass, C.K., Rosenfeld, M.G. (1999). Coactivator and corepressor complexes in nuclear receptor function. Curr. Opin. Genet. Dev. 9, 140-147.

Yang, L., Guerrero, J., Hong, H., DeFranco, D.B., Stallcup, M.R. (2000). Interaction of the tau 2 transcriptional activation domain of glucocorticoid receptor with a novel steroid receptor coactivator, Hic-5, which localizes to both focal adhesions and the nuclear matrix. Mol. Biol. Cell 11, 2007-2018.

Yang-Yen, H.F., Chambard, J.C., Sun, Y.L., Smeal, T., Schmidt, T.J., Drouin, J., Karin, M. (1990). Transcriptional interference between c-Jun and the glucocorticoid receptor: mutual inhibition of DNA binding due to direct protein-protein interaction. Cell 62, 1205-1215. 


\section{Figure legends:}

Figure 1. Structural features or the Glucocorticoid Receptor. Functional domains of human (h), mouse (m) and rat (r) GR include an activation function (AF) 1, a DNA binding domain (DBD), a hinge region (h) and a ligand binding domain (LBD) overlapping with the ligand-dependent AF2.

\section{Figure 2. The different modes of mutual crosstalk between GR and other}

transcription factors. GR and other transcription factors (TFs) modulate each other's activity in a DNA binding-dependent $(\mathrm{A}, \mathrm{B})$ or DNA binding-independent manner $(\mathrm{C}, \mathrm{D})$. (A) Composite response elements (RE) contain binding sites for GR and the other TF. Both GR and the other TFs bind DNA, and the crosstalk results in either enhancement or repression of transcription. (B) An overlapping RE is a single binding motif for both GR and the other TF. Binding of GR blocks the recruitment of the other TF, resulting in transcriptional repression. (C) At a simple TF RE, GR interacts with the DNA-bound TF. The crosstalk results in either enhancement or repression of transcription. (D) At a simple glucocorticoid RE (GRE), other TFs interact with the DNA-bound GR to either enhance or repress transcription. Examples of TFs are given for each mode, with the reported outcome of the crosstalk indicated as positive or negative (see text for details).

Figure 3. Mutations in the GR DNA binding domain and their effect on the crosstalk with other transcription factors. Schematic representation of the zinc finger structure of GR DBD. The numbering corresponds to amino acid positions in human GR. When mutated, circled residues abrogated the crosstalk with other transcription factors, whereas squared residues did not (see text for details). 
Figure 4. Mutations in the GR ligand binding domain not affecting the crosstalk with other transcription factors. (A) Sequence of the LBD/AF2 domain of human GR. The residues marked in red form the 12 helices of the LBD. The boxed residues form the so-called AF2 helix (helix 12), involved in the interaction with LxxLL motif-containing co-activators. (B) 3D model of agonist-bound GR LBD. The model was generated with the KiNG viewer applet at www.rcsb.org, using the coordinates from Bledsoe et al. (2002). The AF2 helix is shown in green. Mutation of the residues underlined in A and shown in black in B did not affect the crosstalk with other transcription factors, while decreasing or abolishing the in vitro interaction with some co-activators (see text for details). 


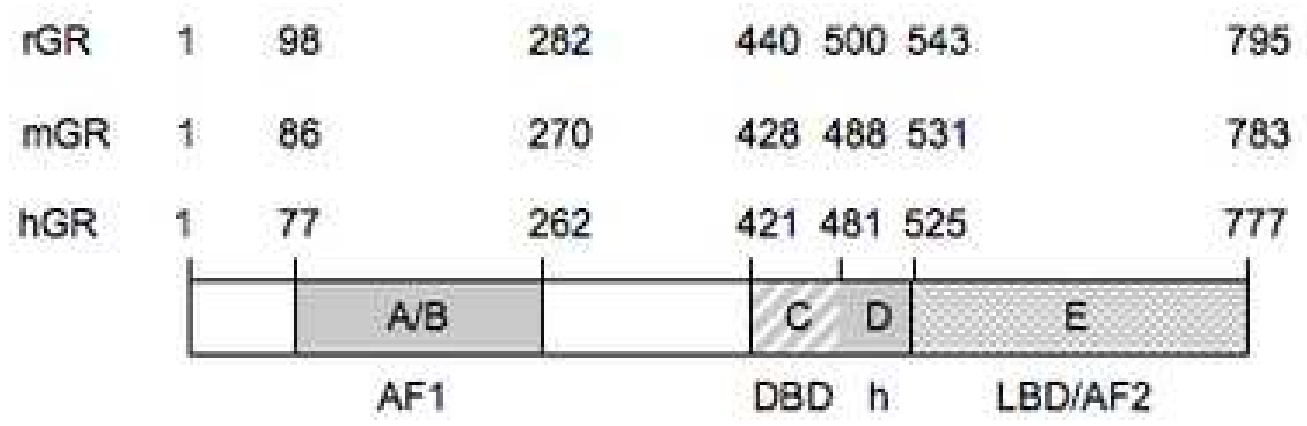

Fig. 1 
A

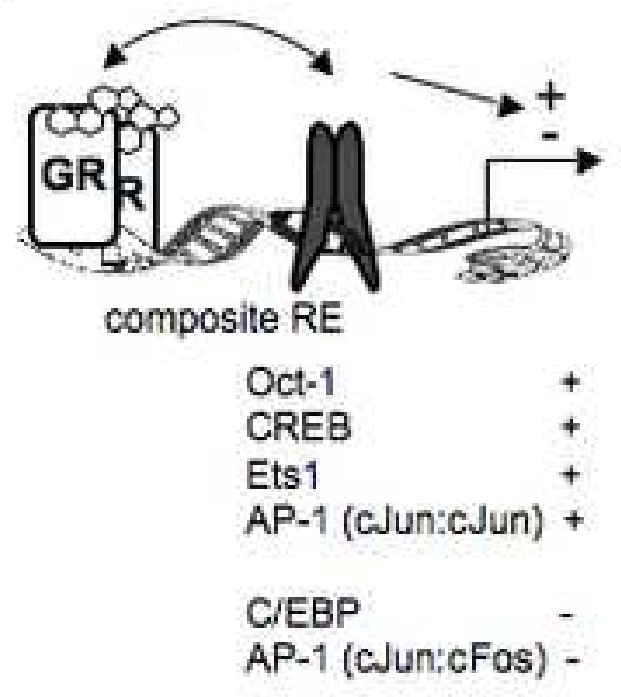

C

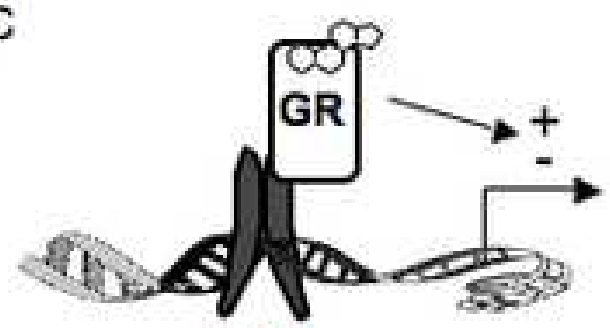

TF-RE

AP-1

$\mathrm{NF}-\mathrm{xB}$

PU.1/Spi-1 -

Smad3,4 -

T-bet

Oct-1/2

STAT6

IRF3

COUP-TFII +

STAT5
B

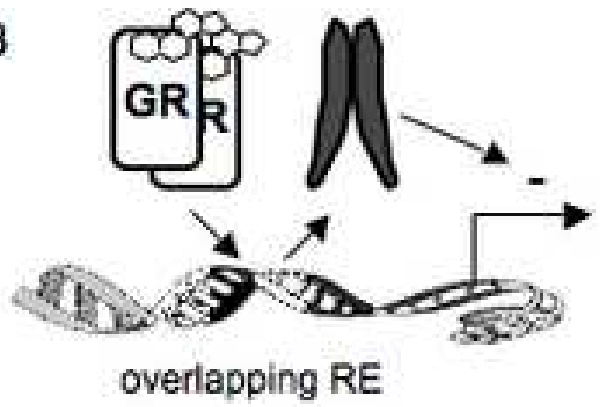

TFIID

Oct-1

D

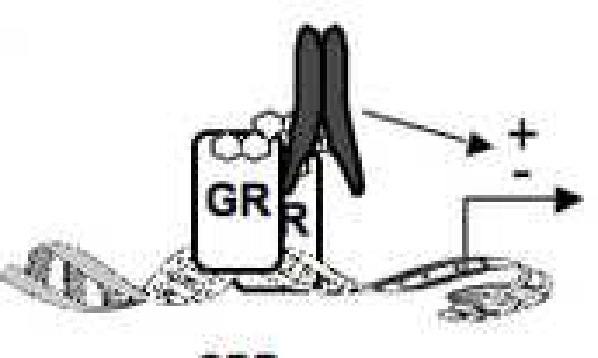

GRE

AP-1

NF-K B

PU.1/Spi-1 -

STAT5

COUP-TFII -

Smad6

T-bet

Oct-1/2 +

Fig. 2 


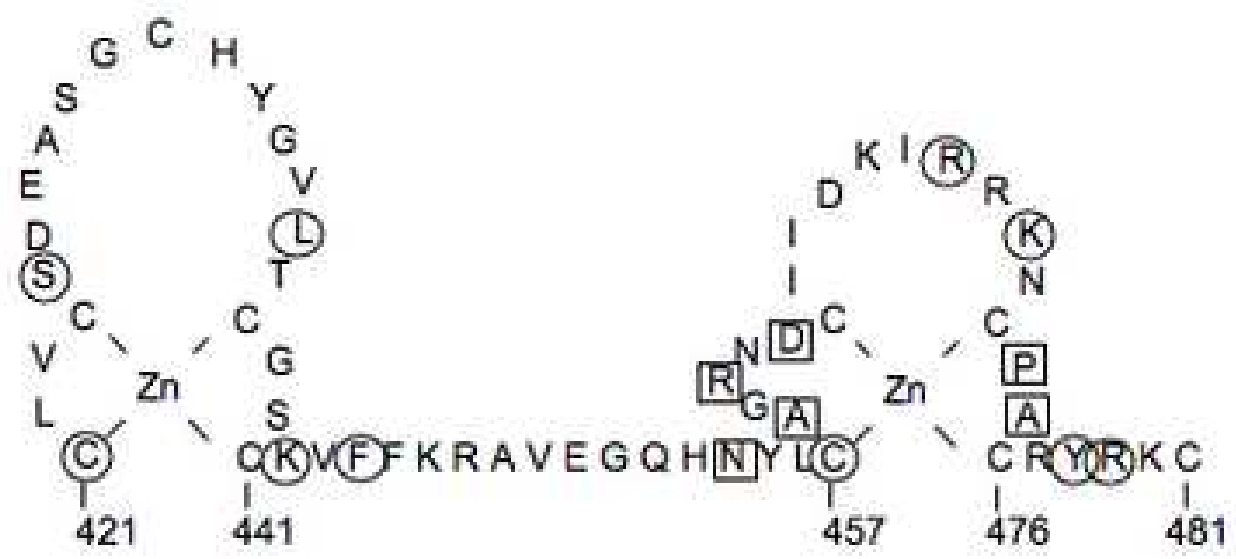

Fig. 3 
A

\$3TLVSLLEVIEPEVLYAGYDSSVPDS TWRIMTTLNMLGGROVIAAYKWA KAIPGFRNLHLDDQMTLLQYSWMFLMAFALGWRSYRQSSANLLCFAPD 641

LIIN EQRM TLPC MYDOCKHML YVSSELHRL QVS YEEYLCMKTLLLLSSV PKDGLKS QELFDEIRMTYIKELGKAIVKREGNSSQNWQRFYQLTKLLDS MHEV VENLLN YCFOTFLDKTMSIEFP EMLAE IITNDIPKYSNGNIKKLLF Hok $7^{77}$

B

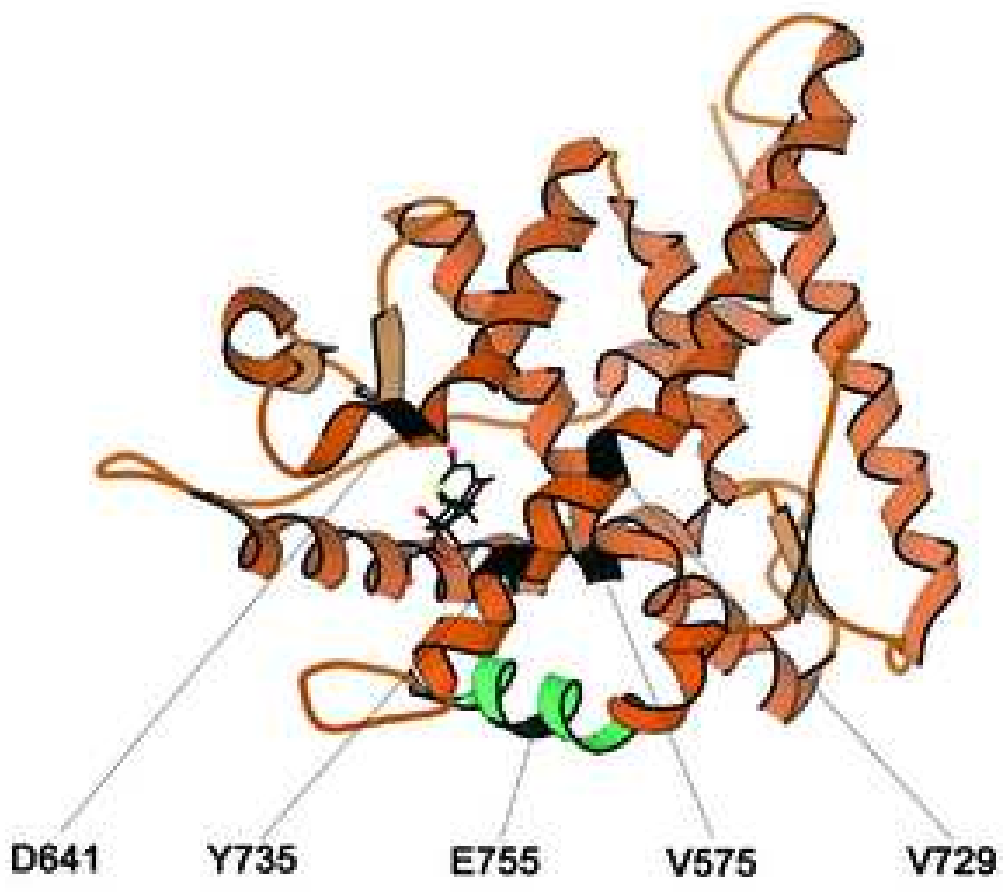

